\title{
Advancements in Host-Based Interventions for Influenza Treatment
}

\author{
Tsz-Fung Yip ${ }^{1}$, Aisha Sami Mohammed Selim¹, Ida Lian² and Suki Man-Yan Lee ${ }^{1 *}$ \\ ${ }^{1}$ HKU-Pasteur Research Pole, School of Public Health, The University of Hong Kong, Hong Kong, Hong Kong, \\ ${ }^{2}$ School of Life Sciences and Chemical Technology, Ngee Ann Polytechnic, Singapore, Singapore
}

OPEN ACCESS

Edited by:

Alan Chen-Yu Hsu,

University of Newcastle,

Australia

Reviewed by:

Stavros Selemidis,

Monash University, Australia

Anastasia N. Vlasova,

The Ohio State University,

United States

*Correspondence:

Suki Man-Yan Lee

suki@hku.hk,

myleesuki01@gmail.com

Specialty section:

This article was submitted to Microbial Immunology,

a section of the journal

Frontiers in Immunology

Received: 13 April 2018

Accepted: 22 June 2018

Published: 10 July 2018

Citation:

Yip TF, Selim ASM, Lian I and Lee SMY (2018) Advancements

in Host-Based Interventions

for Influenza Treatment.

Front. Immunol. 9:1547. doi: 10.3389/fimmu.2018.01547
Influenza is a major acute respiratory infection that causes mortality and morbidity worldwide. Two classes of conventional antivirals, M2 ion channel blockers and neuraminidase inhibitors, are mainstays in managing influenza disease to lessen symptoms while minimizing hospitalization and death in patients with severe influenza. However, the development of viral resistance to both drug classes has become a major public health concern. Vaccines are prophylaxis mainstays but are limited in efficacy due to the difficulty in matching predicted dominant viral strains to circulating strains. As such, other potential interventions are being explored. Since viruses rely on host cellular functions to replicate, recent therapeutic developments focus on targeting host factors involved in virus replication. Besides controlling virus replication, potential targets for drug development include controlling virus-induced host immune responses such as the recently suggested involvement of innate lymphoid cells and NADPH oxidases in influenza virus pathogenesis and immune cell metabolism. In this review, we will discuss the advancements in novel host-based interventions for treating influenza disease.

Keywords: host factors, influenza, cytokines, metabolism, immunomodulation

\section{INTRODUCTION}

Influenza remains a source of public health concern. Influenza A virus (IAV) has been the cause of historical noxious pandemics, such as the Spanish flu 1918 H1N1, Asian flu H2N2 1957, Hong Kong H3N2 flu 1968, and more recently the pandemic of H1N1 2009 (Swine flu). Influenza also causes seasonal epidemics and outbreaks with high morbidity and mortality rates such as the 2015 H1N1 outbreak in India $(1,2)$. The error-prone nature of the viral RNA polymerase (RdRP) and virus' capacity for genetic re-assortment (antigenic drift and shift) result in the viral components' susceptibility to mutations, allowing the viruses to evade the immune system and increases their resistance to control strategies.

Currently, influenza vaccination and two classes of antiviral drugs-M2 ion channel blockers (amantadine and rimantadine) and neuraminidase (NA) inhibitor (oseltamivir, zanamivir, and peramivir) - and the novel treatment option using polymerase inhibitor (favipiravir) are considered as mainstays in influenza infection treatment and control. The use of influenza vaccinations remains challenging due to antigenic drifts and shifts, with seasonal variation of new circulating species. Production of vaccine is time consuming with efficacy concerns, especially in the case of pandemic. Variations in vaccine efficacy caused by age should be aware, with studies suggesting that vaccineconferred protection may not be optimal in certain age groups (3).

The disadvantages of using the conventional antiviral drugs have also been a concern. Significant levels of resistance to both classes of drugs have been repeatedly reported $(4,5)$. High level of 
resistance (up to 91\%) to M2 blockers has been reported in $\mathrm{H} 3 \mathrm{~N} 2$ virus strain in American isolates (6). Resistance has also been reported in $\mathrm{H} 5 \mathrm{~N} 1$ virus (7). IAV resistance to NA inhibitors has also become an increasingly prevalent concern, with the recent highly fatal outbreak of influenza A(H1N1)pdm09 in India 2015 associated with oseltamivir drug resistance $(8,9)$. In addition, a large cluster of influenza A(H1N1)pdm09 viruses in Japan was found to have increased oseltamivir and peramivir drug resistance (5). There is an urgent need to search for alternative targets to treat influenza virus infections, including non-viral targets such as host cellular factors; which are promising as viruses rely on the host machinery for replication. While host immune response is intended to confer a degree of protection against the infection, an impaired or exaggerated host immune response could be detrimental-IAV H5N1 and H7N9 virus infection was reported to exaggerate aberrant cytokine release, resulting in a cytokine storm that caused accelerated host death (10-12).

Many recent studies have focused on the investigation of targeting host factors to control virus replication as well as modulate immune response, which we have previously evaluated (13). In this review, we will discuss the latest studies (in the past 5 years) on the investigation of novel host-based approaches with potential for influenza treatment.

\section{STRATEGIES TARGETING HOST CELL MACHINERY}

The replication cycle of IAV can be grossly divided into four different stages: (1) entry, (2) genome nuclear import, (3) replication and protein synthesis, and (4) genome nuclear export, apical transport, assembly, and budding. As an obligate intracellular pathogen, IAVs are heavily dependent on host machinery for replication and propagation. To this extent, studies employing genome-wide RNA interference (RNAi) to screen for host factors involved in IAV replication cycle have been performed $(14,15)$ and an increasing number of approaches targeting these host factors to control IAV replication have been investigated.

\section{Entry of IAV}

Entry of IAV into the host cell is divided into several steps $(16,17)$. First, hemagglutinin (HA) on the surface of IAV binds to the terminal $\alpha$-sialic acid on the host cell receptor. This induces the internalization of the viral particle by clathrin-dependent, caveolin-, and clathrin-independent endocytosis (18). Macropinocytosis was revealed as an alternative entry pathway for IAV (19), which subsequently enters the canonical endocytic pathway $(20,21)$. The vesicle-containing viral particle forms an early endosome (also known as sorting endosome), which matures into a late endosome as the endocytic pathway progresses. A gradual decrease in intraluminal $\mathrm{pH}$ from $\mathrm{pH} 6.5$ to 5.0 , mediated by V-ATPase proton pump (22), takes place as the endosome matures $(23,24)$. This $\mathrm{pH}$ drop in the endosomal lumen induces a conformational change in $\mathrm{HA}$, which is activated by proteolytic cleavage to generate HA1 and HA2 from precursor molecule HA0 $(25,26)$. This conformational change triggers the fusion of the viral envelope with the endosomal membrane, releasing the viral genome into the cytoplasm.

Acidification of the endosome causes the subsequent acidification of viral lumen via the IAV M2 proton channel (27), which in turn promotes the dissociation of M1 layer from both the viral envelope (24) and the viral ribonucleoprotein (vRNP) complex (28). Interestingly, a sharp decrease in $\mathrm{pH}$ from neutral to an acidic $\mathrm{pH}$ of 5.0 as utilized by acid bypass has been observed to be sub-optimal for viral replication. It is hence proposed that a gradual decrease in endosomal $\mathrm{pH}$ is necessary for sequential reduction in viral stiffness, dissociation of M1 from the NP in the vRNP complex, destabilization of M1 layer from the viral envelope, and the eventual conformational change of the HA for the release of viral genome and proteins to the cytoplasm from late endosome (24).

\section{Inhibition of Proteolytic Cleavage of HA}

Proteolytic cleavage of HA0 to HA1/HA2 is an important step in IAV replication. This cleavage relocates HA2, converting previously uncleaved HA0 to a metastable conformation that induces membrane fusion at acidic $\mathrm{pH}$ (29). Inefficient cleavage and activation of HA leads to low infectivity (30). As identified proteins encoded by the viral genome do not possess proteolytic properties, the virus is dependent on host protease for the cleavage of HA. This provides a potential target to control IAV infection. HA is commonly cleaved by trypsin-like proteases at the single arginine residue at position 329. Human airway epithelium serine proteases HAT and TMPRSS2 were identified as the host factors for cleavage at this residue (31).

Aprotinin, purified from bovine lung (32), is a protease inhibitor with a long history of clinical use as an antifibrinolytic agent in cardiac surgery (33). Its potential as an anti-IAV drug has been recognized for over a decade (34) and has been shown to reduce the infectivity of a broad spectrum of IAV strains $(34,35)$ both in vitro (26) and in vivo (36). Once withdrawn from the Western drug market due to its association with mortality (33), aprotinin has been approved as a locally administered, small-particle aerosol drug for the treatment of IAV infection in Russia (36). However, side-effects associated with the systemic administration of aprotinin raises the need for an alternative protease inhibitor for use in treatment of IAV infections.

Camostat, a serine protease inhibitor, was reported to demonstrate anti-IAV potential in mice dating back to 1996 (37), but little to no research has been conducted to develop it into an anti-IAV treatment. It was revisited and proven to be one of the most efficient serine protease inhibitors for the inhibition of IAV replication in primary human tracheal epithelial cells in vitro when tested compounds were used at similar molarities (35). At present, camostat is widely administered for the treatment of liver fibrosis, chronic pancreatitis, and cancer $(38,39)$, making it a highly promising candidate for drug repurposing. Despite the lack of association between camostat and increased mortality (as with aprotinin), reports of camostat potentially inducing acute eosinophilic pneumonia (38) warrants the need for careful consideration and further research into the repositioning of drugs from the same class. 
Highly pathogenic IAV, such as the $\mathrm{H} 5$ and $\mathrm{H} 7$ subtypes, are reported to have HA cleavage sites rich in basic residues (30). The polybasic nature of the cleavage sites provides multiple targets for a broad spectrum of proteases, including the more ubiquitously expressed intracellular proteases such as furin (40). This increased protease spectrum could be utilized by these viruses for the activation of HA prior to viral budding, allowing for evasion of potential inhibition by exogenously administered serine protease inhibitors. Furthermore, an in vivo study utilizing mice treated with a single protease inhibitor prior to infection with $\mathrm{H} 7$ virus bearing a polybasic cleavage site showed poor efficacy despite good results were obtained for infection with H1N1 virus bearing single cleavage site (41), suggesting strain specificity in using serine protease inhibitors to treat IAV infections.

\section{Inhibition of Endosomal Acidification}

Endosomal acidification is required for the release of IAV genome (in the form of a vRNP complex) into the cytoplasm (24). Research has shown that an increase in endosomal $\mathrm{pH}$ during the early phases of infection could inhibit IAV infection in vitro (42), bringing to light the possibility of controlling IAV infection through the prevention of endosomal acidification.

The V-ATPase inhibitor bafilomycin A1, when used at high concentrations (10-100 nM) has been proven to inhibit IAV replication through the efficient suppression of V-ATPase $(43,44)$. However, prominent cytotoxicity to host cells was also observed at such concentrations (44). Interestingly, lower concentrations (0.1 nM) of bafilomycin A1 lack inhibitory effects on V-ATPase attenuated IAV replication due to disruption of endosomal trafficking. Thus, bafilomycin A1 is suggested to exert its antiviral function via distinct mechanisms at differing concentrations.

Diphyllin, isolated from the plant Cleistanthus collinus, is a natural compound able to induce a V-ATPase inhibitory effect (45). In contrast to bafilomycin A1, diphyllin is well-tolerated in vitro without inducing obvious cytotoxic effects (46). Most notably, diphyllin is found to effectively inhibit replication of viral strains resistant to amantadine and/or oseltamivir (46). Since drug resistance to these widely administered antivirals is of major public health concern (13), diphyllin is regarded as a promising antiviral against drug-resistant IAV strains.

\section{Controlling Cholesterol Homeostasis}

The release of IAV genomic material during replication requires the fusion of the endosomal membrane with the viral envelope. Since cholesterol plays a major role in controlling the fluidity of the lipid bilayer in cells, it is hence suspected to have a role in the infection cycle of IAV.

Interferon-induced transmembrane proteins (IFITMs) are proteins expressed in many vertebrates (including humans) and are found on the plasma membrane, the membranes of early and late endosomes, as well as on lysosomes $(47,48)$. While humans express IFITM1, IFITM2, IFITM3, IFITM5, and IFITM10, only IFITM 1, 2, and 3 are both immune-related as well as interferon (IFN)-inducible (48), and have been observed to restrict the replication of different viruses, including IAV (49). Studies suggest that IFITMs limit viral infection by reducing membrane fluidity and hence restrict the hemifusion (the mixing of lipid bilayer without the release of viral content) of viral and endosomal membranes (50), probably via the disruption of cholesterol homeostasis of late endosomes, where viral fusion and genome release conventionally take place (51). A recent study using RNAi also demonstrated that cholesterol homeostasis can be regulated via acid phosphatase 2 (ACP2)-mediated Niemann-Pick C2 activity and impaired the membrane fusion of IAV and influenza B virus (IBV) (52), further suggesting the importance of controlling cholesterol homeostasis in the release of viral genome to cytoplasm.

On the contrary, later studies suggest that IFITM3 exerts its antiviral activity in a cholesterol-independent manner, showing that an increase in cholesterol composition of late endosomal membranes fail to inhibit viral membrane fusion (53). In addition, studies suggested the accumulation of cholesterol level in the late endosome does not inhibit the IAV genome release into cytoplasm $(54,55)$.

With the modulation of cholesterol levels in host endosomal membrane as a mean to inhibit IAV host cell entry is still under debate, further studies are required before clear conclusions can be drawn.

\section{Other Possible Targets for IAV Entry Inhibition}

By comparing the miRNA profiles of the IAV-permissive HEK 293T cells and (less permissive) HeLa cells, miRNA-33a has been identified as a negative regulator for IAV infection via the inhibition of archain 1 (ARCN1, also known as $\delta$-COPI) (56). ARCN1 is a subunit of the COPI complex that is required for intracellular trafficking and endosome function (57), depletion of which has been reported to inhibit IAV infection (14). Despite impaired IAV internalization caused by ARCN1 depletion via siRNA $(56,58)$, it was not able to recapitulate through acute inhibition of COPI complex by pharmaceutical means (58). It is hypothesized that the long-term (lasting days) perturbation on ARCN1 by RNAi affected the general endosomal trafficking network, a phenomena which cannot be recapitulated by acute pharmaceutical inhibition to block IAV infection (58). The potential of targeting ARCN1 for IAV treatment deserves further investigation, despite the favorable results from RNAi studies.

\section{Blocking the Nuclear Import of vRNP Complex}

Nuclear import of vRNP complexes from the cytoplasm following fusion of the viral and the endosomal membrane is required for replication to take place (59). An early study suggested that vRNP complexes could be transported to the periphery of the nucleus (60), while recent studies report that vRNP complexes utilize the importin- $\alpha$-importin- $\beta 1$ (IMP $\alpha$-IMP $\beta 1)$ system for nuclear import $(59,61)$ and lacking of importin- $\alpha 7$, in an importin- $\alpha 7$ knockout mouse model were found to be resistant to IAV infection (62).

Ivermectin has long been clinically administered for the treatment of parasitosis (63), but has recently come to attention as a potential inhibitor of $I M P \alpha / \beta$ (64). Ivermectin inhibition of IMP $\alpha / \beta$ has shown to inhibit the replication of RNA viruses such as dengue virus and HIV-1 (64). Ivermectin was recently tested for the inhibition of IAV in vitro, with nuclear import of vRNP 
complex (of both wild-type and antiviral MxA escape mutant) efficiently inhibited (65). Given ivermectin's longstanding record of clinical applications and FDA-approved status, repurposing of this drug for the treatment of IAV should be considered, especially while under threat of pandemic IAV outbreak.

\section{Genomic Replication and Protein Synthesis}

Following the import of the vRNP complex into the nucleus of the host cell, RdRP uses the vRNA as a template to synthesize mRNA or cRNA. Synthesized cRNA remains in the nucleus for new vRNA generation, while mRNA is exported out of the nucleus for translation. Viral protein products are either transported to the cell surface via Golgi (in case of HA and NA) or imported back into the nucleus to bind with vRNA, forming new vRNP complex (59). Numerous host factors are involved in this process and hence could be possible targets for therapeutic intervention.

\section{Regulation of the Splicing of Pre-mRNA}

Out of the eight genome segments of IAV, the M and NS segments are well known for undergoing splicing to generate at least two different mRNAs per individual segment $(66,67)$. Cdc2-like kinase 1 (CLK1) is a kinase which regulates alternative splicing of pre-mRNA (68). Inhibition of CLK1 by the chemical TG003 or knockdown of CLK1 is shown to cause a decrease in M2 mRNA generation and disrupt downstream M2 protein expression, prominently reduced IAV propagation (15).

Clypearin and corilagin were both found to be potent antiIAV compounds, with a higher therapeutic index than TG003 in vitro (69). Clypearin is isolated from herbs used by Chinese medicine practitioners for treating respiratory tract diseases (69), while corilagin is isolated from medicinal plants and herbs. The identification of effective compounds and the systemic investigation of the use of traditional Chinese medicine (TCM) in the treatment of IAV infection open new frontiers in research and therapeutics.

\section{Inhibition of mRNA Export}

During replication, viral mRNA is exported from the nucleus to cytoplasm, where protein synthesis takes place. Human RNA polymerase II activity is found to be correlated with IAV replication through the inhibition of nuclear export of certain viral mRNAs, such as M1 mRNA (70).

Cyclosporine A (CsA) is a FDA-approved drug with immunomodulatory functions (71) that has been found to have an anti-IAV effect in both cyclophilin A (CypA)-dependent and -independent manners (72). The CypA-dependent effect was found to correlate with nuclear export of vRNP complex (see Targeting Nuclear Export Complex). The CypA-independent effect caused inhibition of host RNA polymerase II. CsA is a prospective drug candidate for treatment of IAV infections with a relatively high barrier for development of intrinsic drug resistance, as opposed to commonly used antivirals (73).

Nuclear RNA export factor 1 (NXF1) is a host factor that has been identified to be involved in the nuclear export of IAV mRNA. The knockdown of NXF1 in HEK 293T cells revealed prominent viral mRNA nuclear retention in host cell nucleus (74). Protectin D1 (PD1), an endogenously produced lipid in the respiratory tract, has been identified to have potent anti-inflammatory and antiviral effects (75). PD1 production was notably found to be reduced in the lungs of IAV-infected mice. Therapeutic administration of PD1 was shown to significantly reduce IAV mRNA expression, lower lung viral titer, as well as improve survival of IAV-infected mice. Mechanistic studies revealed attenuated cytoplasmic translocation of viral mRNA with such treatment. A decrease in recruitment of viral transcripts to NXF1 was observed while nuclear export of host RNA remained largely unaffected, suggesting a role of PD1 in regulating NXF1 in nuclear export of viral RNA. Natural PD1 expression in the human airway makes this an ideal candidate for novel therapeutics in the treatment of IAV infection.

\section{Inhibition of mRNA Translation}

The eukaryotic initiation factor-4A (eIF4A) family plays an important role in protein translation $(76,77)$. eIF4A impairment has been proven to be related to antiviral activity in a broad spectrum of RNA viruses in vitro (78), with inhibition of IAV mRNA translation (79). The eIF4A inhibitors, silvestrol and pateamine A were demonstrated to arrest viral protein synthesis, thus blocking viral genome replication in vitro (80). Although both silvestrol and pateamine A caused high cytotoxicity at the concentration required effective for IAV inhibition, drugs targeting mRNA translation for various diseases have been approved by FDA or are under active development (81). As such, inhibition of IAV infections by disrupting mRNA translation may well be a therapeutic approach in the future.

\section{Inhibition of HA Maturation}

Post-translational modifications during protein maturation ensure proper function of proteins, with proteins of IAV no exception. Nitazoxanide, a FDA-licensed drug used to treat enteritis, was found to be effective in controlling IAV infection by interfering with $\mathrm{HA} \mathrm{N}$-glycosylation as well as intracellular trafficking in host cell and eventually led to a reduction in viral budding (82). Despite the mechanism of nitazoxanide being presently unknown, its ability to inhibit replication of numerous viruses [IAV, respiratory syncytial virus, coronavirus, hepatitis $B$ virus, and many others (83)] suggests that it may act on host machinery. The drug has also been proven in vitro to inhibit the propagation of many circulating strains of human IAV, including those resistant to oseltamivir or zanamivir (84). Nitazoxanide has a high barrier of resistance to IAV (83) and other viral strains resistance to neuraminidase inhibitors (85), making it a very promising therapeutic target for IAV treatment. The drug is currently under phase III clinical trials (83).

\section{Nuclear Export, Assembly, Apical Transport, and Viral Budding}

In the later stage of viral replication, viral RNAs of IAV packed with RdRP and NP (known as vRNP complexes) are exported from the nucleus (59), assembled (86), and transported to the plasma membrane [apical in polarized cells (87)] for budding. 


\section{Inhibition of Nuclear Export \\ Targeting Nuclear Export Complex}

Exportin 1 (XPO1, also known as CRM1) is well known for its function in the nuclear export of protein (88) and RNA, including viral RNA (89). Similar to HIV (89, 90), IAV viral RNA does not directly bind to XPO1 but is instead held together by several viral proteins. The viral nuclear export protein (NEP, or previously known as NS2) and the vRNP complex have been proposed as the nuclear export complex (91). Cellular XPO1 has been proven to be crucial in the nuclear export of the vRNP complex, with early studies using leptomycin B (LMB), a potent XPO1 inhibitor, revealing that in vitro inhibition of XPO1 led to nuclear retention of vRNP complex $(92,93)$. However, LMB was deemed unsuitable for development as a potential drug in the phase I clinical trial due to observed cytotoxic effects (94).

Verdinexor (also known as KPT-355) is a new bioavailable selective inhibitor of XPO1. It has been shown to be effective against different strains of IAVs both in vitro and in vivo as prophylactic and therapeutic treatments $(95,96)$. It is worth mentioning that delayed administration of verdinexor at day 4 post-infection was still deemed beneficial, with reduced viral load in vivo (96). This suggests a prolonged therapeutic time window when compared to the mainstay antiviral drugs such as oseltamivir, where recommended administration is at the early stage of infection (within 48 h of symptom onset) (97). Currently, verdinexor has passed the phase I clinical study trials, suggesting that it does not pose severe cytotoxic effects as LMB does.

In addition, a recent report demonstrated that a new drug, DP2392-E10, which binds and inhibits the function of XPO1, can suppress IAV replication in vitro (98) further strengthens the concept of IAV intervention by targeting XPO1.

Viral M1 protein is crucial in assisting the nuclear export of vRNP complex. It was commonly suggested that M1 protein links vRNP complex to viral nuclear export protein NEP which interacts with XPO1 for nuclear export (59). Thus, viral M1 protein may serve as a target to inhibit nuclear export of vRNP. As previously mentioned (see Inhibition of mRNA Export), CsA inhibits IAV replication via both CypA-dependent and -independent mechanisms. A recent study using a transgenic mice overexpressing CypA showed greater resistance to IAV challenge (99). In the CypA-dependent mechanism, CsA enhances the binding of CypA to M1 protein (72), increases the self-association of M1, and hinders M1 nuclear import (100). CsA also promotes the CypA-dependent degradation of viral M1 protein $(72,101)$. CsA seems to be a promising drug to inhibit the nuclear export of vRNP complex by inhibiting viral M1 protein stability and function.

Recently, CD151, a tetraspanin (defined by four transmembrane domains with conserved residues) that is expressed abundantly in lungs and interacts with integrins has been implicated in the regulation of IAV replication in vitro and in vivo (102). Knockdown of CD151 in primary human nasal epithelial cells resulted in the nuclear retention of host XPO1, viral NP, NEP, and $\mathrm{M} 1$ proteins, with an increased survival rate observed in IAVinfected CD151 knockout mice. Co-immunoprecipitation assays suggest that CD151 interacts with viral NP, M1, and NEP proteins (102); however, the exact domains involved in interaction and the mechanism of CD151 function in nuclear export remain unclear. Given that a small molecule inhibitor for CD151 is now under development (103), more data revealing the role of CD151 in IAV infection and subsequent use in targeting CD151 as anti-IAV therapy is anticipated.

\section{Targeting the Raf/MEK/ERK Pathway}

During IAV infection, Raf/MEK/ERK signaling cascade is activated, while the inhibition of MEK by U0126, probably mediated via myosin (light chain) (104), a known motor protein, impairs the nuclear export of vRNP complexes (105). Suppressing IAV replication by inhibition of Raf/MEK/ERK signaling cascade has been illustrated both in vivo (106) and in vitro (105). The replication of IBV (107) as well as Borna disease virus (108) was shown to be inhibited by U0126, suggesting the versatility of this approach in controlling infection by different viruses. Despite being effective when administered locally to lungs via aerosol, U0126 has little effect when administered orally (106).

Another MEK inhibitor, CI-1040 (also known as PD184352) was shown to have high potency against IAV in vitro (106). CI-1040 has completed phase II clinical trials as an anti-tumor drug, with the application of CI-1040 as a potential anti-IAV drug candidate recently revisited. Unlike U0126, CI-1040 is orally bioavailable and oral administration of CI-1040 at $48 \mathrm{~h}$ post-infection protected $60 \%$ of the IAV-infected mice, while the oseltamivir-treated group experienced a $100 \%$ death rate (109). Oseltamivir is known to be effective only when administered in the early stages of IAV infection. This suggests the potential use of CI-1040 as an agent used in IAV treatment due to its potentially longer therapeutic time window than mainstay antivirals.

Formyl peptide receptor 2 (FPR2) located at the host cell surface was identified as an ERK stimulator (110). Antagonizing FPR2 promoted the survival of IAV-infected mice (110). Furthermore, FPR2 antagonists have been described to possess antiviral activity against not only IAV but also IBV infection (111), promoting the idea that antagonizing FPR2 to suppress Raf/MEK/ERK signaling cascade could potentially be a novel approach for the treatment of a broad spectrum of influenza viruses.

\section{Apical Transport of Viral Components}

After the nuclear export of the vRNP complexes, host cell's intracellular transport mechanism is required to deliver vRNP complexes to the host plasma membrane for the assembly of viral RNAs and proteins at the final stage of viral replication. Among the various vesicular compartments found in a cell, the $\mathrm{Rab}_{11 \mathrm{~A}^{+}}$endosomes are known to recycle endocytosed membrane proteins and lipids to the plasma membrane for membrane homeostasis (112), a property utilized by many RNA viruses, including IAV (87, 113-115). IAV progeny virus production was found to be significantly reduced in Rab $11 \mathrm{~A}^{+}$knockdown human cell lines (116). Furthermore, vRNP complex plasma membrane transport perturbation was observed in Rab11A knockdown cells (114, 115); in cells expressing deletion mutant of Rab11 family interacting proteins (87); as well as cells treated with chemicals to interfere microtubule (114). Direct interaction of vRNP complex with Rab11A has also been verified $(114,115)$, demonstrating the dependence of vRNA complex transport on Rab11A ${ }^{+}$vesicles and 
the microtubule network during viral replication. Since Rab11A proteins do not confer any mobile properties to the vesicle, molecular motors such as kinesins are required for the active transportation of vesicles through cytoskeletons.

KIF13A, a kinesin-3 family member, was recently identified as a molecular motor for plasma membrane transportation of vRNP-loaded Rab11A ${ }^{+}$vesicles (117). KIF13A knockdown was found to reduce progeny virus production. Overexpression of a mutant form of KIF13A lacking in motor capacity resulted in disruption of the plasma membrane distribution of vRNP complex during later stages of infection. This data suggest that the apical transport of viral components via Rab11A or KIF13A could potentially serve as therapeutic targets against IAV infection. Further examination is merited.

Tubulin acetylation and deacetylation affects microtubule stability (118). Histone deacetylase 6 (HDAC6) was found to deacetylate $\alpha$-tubulin, one of the subunits of microtubule (119). A study has demonstrated that HDAC6 is involved in IAV replication (120). Inhibition of HDAC6 by tubacin or knockdown of HDAC6 gene resulted in an increase of progeny virus production with vRNP complex redistributed toward the periphery of infected cells. In addition, transportation of HA to the plasma membrane for viral budding was also found to be inhibited by HDAC6. This data suggests that activation of HDAC6 by its stimulant could be a potential approach to anti-IAV therapy, despite HDAC6 stimulants still being under development.

\section{Interference of Viral Budding}

While several studies have suggested IAV transmission between cells through apical membranes (121) and intercellular connections (122), virus budding from cell membranes remains the major route for transmission of viruses to uninfected cells. NA is responsible for the cleavage of sialic acid to prevent the interaction between HA and the host cell during viral budding. Besides, viral NA, viral HA, M1 as well as M2, are also suggested to play an important role in the initiation of the budding process $(123,124)$.

In Section "Controlling Cholesterol Homeostasis," we discussed the involvement of host cholesterol in viral membrane fusion and viral genome release to cytoplasm. Recent studies have demonstrated that host cholesterol may also play an important role in viral budding. It was demonstrated that overexpression of annexin A6 (AnxA6), a phospholipid binding protein, could lead to a decrease in cholesterol levels within the Golgi apparatus and plasma membrane (55), ultimately causing a reduction in egression of progeny virion from infected cells (54). This reduction could be reversed by the addition of exogenous cholesterol (55). Similar to AnxA6 overexpression, addition of a hydrophobic polyamine, U18666A, could reduce cholesterol level in plasma membrane, also inhibited viral replication (55). Since IAV is assumed to bud from lipid rafts (cholesterol-rich plasma membrane domains) (123), it was demonstrated that AnxA6 overexpression or U18666A treatment could hinder progeny virus production by lowering the cholesterol content in the plasma membrane. This hypothesis was strengthened through recent studies resolving the cholesterol-binding site of viral M2 protein, suggesting that IAV M2 clustering (which provides membrane curvature for scission) is mediated by cholesterol (125). A recent report utilizing two different FDA-approved cholesterol-lowering drugs, gemfibrozil and lovastatin, stated that there was reduction in stability and infectivity of progeny virus compared to that replicating within cholesterol-sufficient host cells (126). Taken together, this data suggests that controlling cellular cholesterol content would be an effective alternative with drugs available for repurposing IAV treatment. Further in vivo works are needed to confirm this hypothesis.

The Gi-type G-protein coupled receptor $\alpha 2$-adrenergic receptors ( $\alpha 2$-ARs) have been recently identified as a key host factor involved in IAV replication (127). Apical transport of the viral protein HA is inhibited by low intracellular cAMP level after stimulating the $\alpha 2$-AR-mediated signaling. In vitro stimulation of $\alpha 2$ AR by its agonist clonidine inhibits IAV replication. Therapeutic administration of clonidine reduced pulmonary edema and improved survival rate of IAV-infected mice. Development of a new antiviral targeting the $\alpha 2$-AR-mediated signaling seems promising and deserves further investigation.

\section{Interrupting the Virus Replication Cycle by Combinatory Use Targeting Both Virus and Host Factors}

Although targeting host factors for viral interventions generally provides a better resistance barrier, emergence of resistance may still arise (61). Therefore, combined use of interventions targeting both virus and host factors have been recommended to reduce opportunities for viral development of resistance. One such example would be the combined administration of NA inhibitor (oseltamivir) alongside an anti-host factor [such as V-ATPase inhibitor diphyllin (46), HA maturation inhibitor nitazoxanide (85), FPR2 antagonists (111), and XPO1 inhibitor verdinexor (96)]. While further direct assessment for the ease of emergence of escape mutants between single and combinatory use of drugs is required, the synergistic effects of a combined, multi-drug approach observed thus far highly suggest an increased effectiveness over a single-drug approach.

Table 1 summarizes novel host targets regulating IAV replication. Compared to RNAi, small molecular chemicals remain the best choice as drug candidates due to their fast acting and easy-todeliver properties. Although small molecular chemicals targeting certain host factors aforementioned have yet to be developed, their RNAi-identified involvement in the IAV replication cycle provide leads for the development of new IAV interventions.

\section{REGULATION OF ABERRANT IMMUNE RESPONSES IN IAV INFECTION}

The immune system aims to protect the host from infection and clear the pathogen once an infection occurs. In addition, the complex networks formed between the host physiology and the immune system co-operatively shape the disease outcome; modulations on the networks could alleviate disease severity in IAV infections.

The immunological responses elicited by IAV infection has been reviewed in detail (128-130). At the initial stage of IAV 
TABLE 1 | Advancements on targeting host factors for antivirals.

\begin{tabular}{|c|c|c|c|}
\hline Cellular target & $\begin{array}{l}\text { New potential therapeutic } \\
\text { approach }\end{array}$ & Suggested function & Reference \\
\hline \multicolumn{4}{|l|}{ Viral entry } \\
\hline Serine proteases & Camostat & Inhibits HAO cleavage & Yamaya et al. (35) \\
\hline V-ATPase & Diphyllin & Inhibits endosomal acidification & Chen et al. (46) \\
\hline Acid phosphatase 2 & SiRNA & Indirectly disrupts cholesterol homeostasis & Lee et al. (52) \\
\hline \multicolumn{4}{|l|}{ Nuclear import } \\
\hline Importins & Ivermectin & $\begin{array}{l}\text { Inhibits nuclear import of viral } \\
\text { ribonucleoprotein (vRNP) complex }\end{array}$ & Gotz et al. (65) \\
\hline \multicolumn{4}{|c|}{ Genomic replication and protein synthesis } \\
\hline Cdc2-like kinase 1 & Clypearin & Attenuates M2 splicing & Zu et al. (69) \\
\hline RNA polymerase II & Cyclosporine A & Inhibits viral mRNA export & Ma et al. (73) \\
\hline Nuclear RNA export factor 1 & PD1 & Inhibits viral RNA export & Morita et al. (75) \\
\hline Eukaryotic initiation factor-4A & $\begin{array}{l}\text { a. Silvestrol } \\
\text { b. Pateamine A }\end{array}$ & Inhibits mRNA translation & Slaine et al. (80) \\
\hline \multicolumn{4}{|l|}{ vRNP complex nuclear export } \\
\hline XPO1 & $\begin{array}{l}\text { a. Verdinexor } \\
\text { b. DP2392-E10 }\end{array}$ & Inhibit vRNP complex nuclear export & $\begin{array}{l}\text { a. Perwitasari et al. }(95,96) \\
\text { b. Chutiwitoonchai et al. (98) }\end{array}$ \\
\hline СурА & Cyclosporine A & Promotes M1 degradation & Liu et al. $(72,101)$ \\
\hline CD151 & SiRNA & Inhibits vRNP complex nuclear export & Qiao Y. et al. (102) \\
\hline MEK & $\mathrm{Cl}-1040$ & $\begin{array}{l}\text { Inhibits MEK to suppress phosphorylation of myosin } \\
\text { light chain leading to nuclear retention of vRNP complex }\end{array}$ & Haasbach et al. (109) \\
\hline Formyl peptide receptor 2 (FPR2) & WRW4 & $\begin{array}{l}\text { Inhibits activation of Raf/MEK/ERK by the ligation } \\
\text { of AnxA1 to FPR2 }\end{array}$ & Courtin et al. (111) \\
\hline \multicolumn{4}{|l|}{ Viral component apical transport } \\
\hline KIF13A & To be determined & Blocks vRNP apical transport & $\begin{array}{l}\text { Ramos-Nascimento } \\
\text { et al. (117) }\end{array}$ \\
\hline Histone deacetylase 6 & To be determined & Regulates microtubule stability & Husain et al. (120) \\
\hline$A n \times A 6$ & To be determined & $\begin{array}{l}\text { Reduces plasma membrane cholesterol level } \\
\text { and decreases virion egress or stability }\end{array}$ & Musiol et al. (55) \\
\hline Cholesterol & U18666A & $\begin{array}{l}\text { Reduces plasma membrane cholesterol level and } \\
\text { decreases virion egress }\end{array}$ & Musiol et al. (55) \\
\hline$\alpha 2$-adrenergic receptors & Clonidine & $\begin{array}{l}\text { Reduces intracellular cAMP to impair Influenza } \\
\text { A virus HA plasma membrane transport }\end{array}$ & Matsui et al. (127) \\
\hline \multicolumn{4}{|l|}{ Other } \\
\hline Cholesterol & $\begin{array}{l}\text { a. Gemfibrozil } \\
\text { b. lovastatin }\end{array}$ & Reduces progeny virus stability and infectivity & Bajimaya et al. (126) \\
\hline
\end{tabular}

infection, the respiratory epithelial cells are the primary target for infection. Once the infection is initiated, the recognition of infection is accomplished via the detection of pathogen-associated molecular patterns (PAMPs) by pattern recognition receptors (PRRs) (see Toll-Like Receptors), and lead to the expression and secretion of different cytokines and chemokines, such as IL-6, IL- 8 , tumor necrosis factor (TNF)- $\alpha$, and CCL2 as well as type I and III IFNs. As sentinel cells, alveolar macrophages could also be infected, inducing cytokines and is the main source of type I IFNs $(128,129)$. Type I IFNs are known inducer for the upregulation of death receptor 5 , which is the receptor for TNFrelated apoptosis-inducing ligand (TRAIL), in lung pneumocytes (128). IL-8 and CCL2 produced by both epithelial cells and macrophages act as chemoattractants for neutrophils and monocytes, respectively. Neutrophils are one of the earliest immune cells being recruited to the site of infection (131) with transmigration of neutrophils carry out by adhesion molecules, such as CD11a, CD11b, and CD18 (132). In addition to the antiviral activity of neutrophil-released reactive oxygen species (ROS), defensin and pentraxin (132), uptaking IAV by neutrophils could also help in controlling viral propagation as these cells do not support replication of IAV (133). Besides controlling viral replication, neutrophils also play an important role in guiding the migration of IAV-specific $\mathrm{CD}^{+} \mathrm{T}$-cells in the infection site by secreting and leaving a trail of CXCL12 (134). Infiltrated monocytes will, however, differentiate into macrophages or dendritic cells (DCs). 
The monocytes-derived macrophages are reported to be a permissive host for IAV production (135), sustaining inflammation by producing cytokines in a magnitude larger than that of the resident alveolar macrophages. The monocyte-derived DC as well as the resident airway $\mathrm{CD} 11 \mathrm{c}^{\text {low }} \mathrm{B} 220^{+}$plasmacytoid DC (pDC) and two types of conventional DCs $\left(\mathrm{CD} 103^{+} \mathrm{CD} 11 \mathrm{~b}^{\text {low }}\right.$ and CD $103^{-} \mathrm{CD} 11 \mathrm{~b}^{\mathrm{hi}}$ ) acquire the antigen of the invading pathogen through either direct infection or up-taking infected dead cells (129). In the presence of type I IFNs, DCs mature when encountering PAMPs from invading pathogen (129). Depending on the sub-cellular localization of the antigen, cytosolic and endosomal antigen will be loaded onto major histocompatibility complex (MHC) class I and II molecules respectively (130). Once mature, DCs migrate from the infection site to the draining lymph nodes via the interaction of CCR7 and CCL19/CCL21 $(130,136)$ for antigen presentation via $\mathrm{MHC}$ class I and II to naïve $\mathrm{CD}^{+}$and CD4 ${ }^{+}$T-cells, respectively (137-140). Interestingly, monocytesderived DCs that engulfed the infected dead cells are poor antigen presenters for $\mathrm{CD}^{+} \mathrm{T}$-cells and require the transfer of intact MHC class I/peptide complex to lymph node-resident CD8 $\alpha^{+}$ DCs which are the most efficient antigen-presenting cells to $\mathrm{CD}^{+}$ T-cells (137). In addition to antigen presentation, pDC are well known for their high ability in type I IFNs production to limit viral propagation (141).

Within the lymph node, naïve $\mathrm{CD} 8^{+} \mathrm{T}$-cells are activated by the DCs, differentiate and clonal expand into cytotoxic T-lymphocytes (CTLs) with the aid of various cytokines, including IFN- $\gamma$, IL-12, type I IFNs, and IL2 $(142,143)$, and the help from activated CD4 ${ }^{+}$ T helper cells (144). Differentiated CTLs downregulate their lymph node homing receptor CCR7 and upregulate CCR4 and CXCR3 for the migration to the site of infection. Within the site of infection, CTLs control viral replication by targeting and inducing apoptosis of virus-infected cells via the secretion of perforin and granzymes as well as the ligation of death receptors on the infected cells by TNF, Fas ligand, and TRAIL. On the other hand, $\mathrm{CD}^{+}{ }^{+} \mathrm{T}$-cells are activated by the presentation of MHC class II/ antigen complex by DCs, with co-stimulatory receptors such as CD28 expressed on the T-cells and the ligand for CD28 (CD80 and CD86) expressed on DCs playing an important role (144). Activation of $\mathrm{CD}^{+}{ }^{+} \mathrm{T}$-cells lead to differentiation into different effector cells subsets, including the classical Th1 and Th2, and the more recently identified regulatory $\mathrm{T}$ cells, follicular $\mathrm{T}$ helper cells, Th9, and Th17 subsets (144). Th1 cells regulate to the differentiation of CTLs as mentioned whereas Th2 cells contributes to the activation of B-cells through CD40L. Within the pregerminal center of the lymph node, the follicular $\mathrm{T}$ helper cells interact with antigen-primed B-cells and promote their proliferation. Antigen-primed B-cells differentiates into plasmablast and undergo antibody class-switching in the germinal center (145). Detailed functions of regulatory $\mathrm{T}$ cells, follicular $\mathrm{T}$ cells, Th9, and Th17 cells are discussed elsewhere $(144,145)$. Plasmablasts enter the blood-stream, are recruited to the inflamed tissue, and terminally differentiate into plasma B cells which specialize in the production of antibody for pathogen neutralization, opsonization, and antibody-dependent cell-mediated cytotoxicity, etc. Memory $\mathrm{T}$ - and B-cells are also developed during the maturation process, and has been discussed and reviewed elsewhere (146-149).
A schematic diagram showing a summary of the immune response after IAV infection has been illustrated in Figure 1.

The Yin and Yang theory is always used to describe the importance in balancing the host immune response. In the light of this theory, the treatment strategy aims to suppress the overwhelming activation of the host immune response and in reverse to compensate any unfavorable suppression.

Although adaptive immune responses are important in viral clearance, the immediate innate immunity play an important role in the early control of an infection, and conversely, is a major factor for disease severity due to immunopathology. Dysregulated immune responses caused by viral infections have been implicated in severe disease development $(150,151)$, such as acute lung injury (ALI). ALI in its most severe form, known as acute respiratory distress syndrome (ARDS), is reported to be the most prevalent cause of mortality in IAV-infected patients (152).

Studies suggested that IAV strains could be associated with either over-activating (human infection by avian $\mathrm{H} 5 \mathrm{~N} 1$ and H7N9) $(153,154)$ or suppressing (H1N1, H3N2) (155) immune response.

\section{Regulation of Neutrophil Infiltration and Neutrophil Extracellular Trap}

Recent history has seen the outbreak of IAV pandemics of varying severity takes place at the cost of millions of lives. One such example would be the deadly Spanish flu of 1918, which claimed the lives of 20-50 million of the 500 million people infected worldwide.

The pathological examination of lung sections from mice infected with reconstituted 1918 IAV virus revealed necrotizing bronchiolitis and severe alveolitis in tissue, with neutrophils observed as the predominant inflammatory cell type present (156), suggesting neutrophil involvement in the pathogenesis of IAV infection.

The majority of immune cells in blood circulation are neutrophils; of which they are among the first innate immune cells recruited to the site of infection (131). Neutrophils characteristically control microbial infections by generating bactericidal (157) neutrophil extracellular traps (NETs), consisting of granule proteins, histones, and decondensed chromatin (131). Both protective and destructive role of neutrophils in IAV infections have been described. The contrasting role of neutrophils could be explained by factors such as viral strain and viral dose used in different experimental setup, etc.

The protective role of neutrophils was observed when mice infected with a low, non-lethal dose of IAV H3N2 strain HKx31 displayed neutrophil-mediated viral clearance via phagocytosis $(132,158)$. Depletion of neutrophils has found to enhance viral load in the IAV-infected animals (158).

On the contrary, this protective nature is disputed due to the association of neutrophil-generated NETs. Extensive NET formation was observed in mice infected with PR8, an IAV strain highly pathogenic to mice (159). Histones and myeloperoxidase within the NET induce cell death of lung epithelium and endothelium (157), leading to the loss of integrity of the alveolarcapillary barrier, a characteristic of ALI. Yet, while histones have 


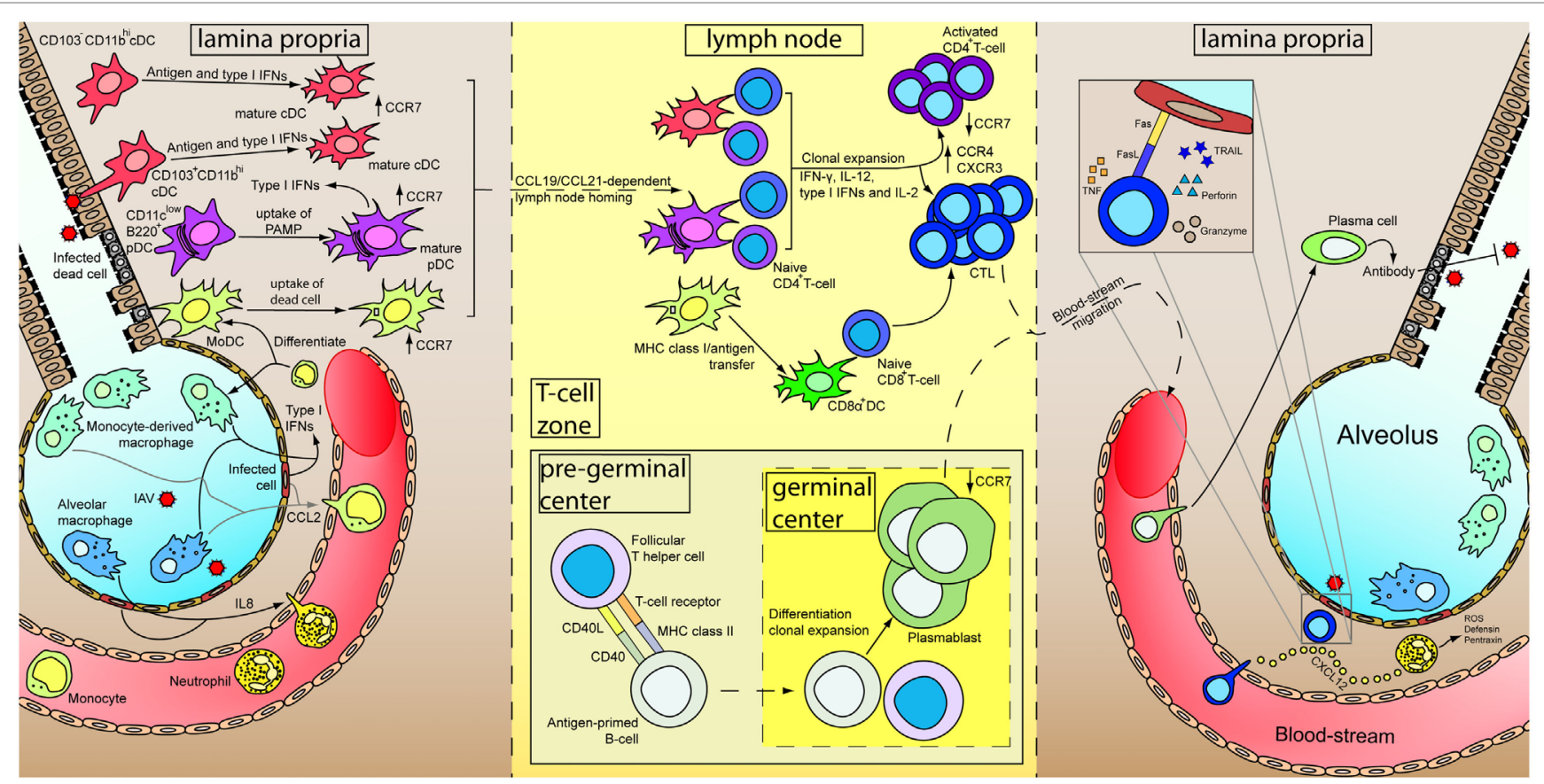

FIGURE 1 | Immune responses of primary influenza A virus (IAV) infection. At the initial stage of infection (left), airway epithelial cells and pneumocytes are major targets for IAV. Various cytokines are secreted by these cells as well as alveolar macrophages to induce inflammation and recruits blood immune cells. Infiltrated neutrophils secrete different antimicrobial products to control viral replication. Besides, CXCL12 is secreted by neutrophils to guide the cytotoxic T-lymphocytes (CTLs) in the later stage of infection. Infiltrated monocytes will further differentiate into monocyte-derived macrophages and monocyte-derived dendritic cells (MoDC). Constant surveying of the airway and uptake of virus-infected dead cells by DCs lead to their maturation. Upregulation of CCR7 results in a CCL19/ CCL21-dependent lymph node homing of DCs. Within the lymph node (middle), MoDCs cross-dress CD $8 \alpha^{+} \mathrm{DC}$. CD4 $4^{+}$and CD8 ${ }^{+}$-cells are activated by DCs in the presence of cytokines and undergo clonal expansion. Antigen-primed B-cells mature with the aid from follicular T helper cells and further differentiate into plasmablasts in the germinal center. Differential expression of receptors upon maturation of T- and B-cells prompt them to leave the lymph node, enter the blood-stream and recruited to the lung. In the inflamed lung (right), neutrophils leave a trail of CXCL12 to guide CTLs migration. Measures utilized by CTLs for killing infected cells are depicted in inset. Plasmablasts further terminally differentiate into plasma cells and increase antibody production for IAV neutralization.

been shown to suppress IAV replication in vitro (160), in vivo study demonstrated that there was increase in lung inflammation and damage in IAV-infected mice treated with histones (161). Interestingly, co-treatment of lethally infected mice with anti-histone antibody and oseltamivir resulted in an increase in animal survival when compared to infected mice groups treated solely with oseltamivir (161).

In agreement with the in vitro and in vivo data, it has been reported that NET produced by cultured neutrophils from patient with H7N9 and severe H1N1 infection increased alveolar epithelial cell permeability (162) leading to ALI. More importantly, plasma NET level positively correlated with the disease severity index (including higher acute physiology and chronic health evaluation II score) and multiple organ dysfunction syndrome (162), further demonstrating the detrimental role of NET in the pathogenesis of severe IAV infections.

Studies have demonstrated the involvement of superoxide dismutase and myeloperoxidase in NETosis, the formation of NET (159). The presence of anti-myeloperoxidase antibody as well as the superoxide dismutase inhibitor (DETC) significantly reduced NETosis. Finally, tetrahydroisoquinolines (163) and a panpeptidylarginine deiminase (PAD) inhibitor, named Cl-amidine (164) have been suggested to inhibit NETosis. Despite it has been reported that during IAV H1N1 infection, PAD4 knockout mice displayed only slight improvement in weight loss and a slight prolonged but no end-point survival advantage was observed compared to WT mice (165), based on the extensive findings presented above, targeting NET to prevent ALI in the severe case of IAV infection, including the highly pathogenic avian IAV, remain promising and may warrant further investigation.

\section{Innate Lymphoid Cells (ILCs)}

Innate lymphoid cells are cells of lymphoid lineages that do not express antigen-specific B- or T-cell receptors (166). Similar to T-helper cells, they are classified into subsets by their ability to produce type 1 (Th1), type 2 (Th2), and type 3 (Th17 and Th22) cytokines.

Previous studies confirmed the involvement of ILCs of group 2 linage (ILC2) in IAV infection and airway inflammation $(166,167)$. On the positive side, during the recovery phase of IAV infection, ILC2 expresses amphiregulin which promote airway epithelium repair $(166,168)$, thus facilitating the recovery of the infected lung.

On the other hand, in response to IL-33 produced by macrophages, DCs, and NKT cells, ILC2 secretes IL-5 and IL-13 and induce airway hyper-responsiveness. Recruitment of eosinophils 
by IL-5 to the lung also mediates airway inflammation (166). Since eosinophilia is a characteristic of allergic asthma and influenza is a major cause for morbidity and mortality in asthma patients (166), it will be of particular interest to investigate the role of ILC2 in IAV infection, particularly in asthma patients.

ILC1s have been initially described as immature NK cells residing in the liver and share many phenotypic similarities with NK cells (169). It was recently appreciated that tissue-resident ILC1s other than the previously recognized NK cells are the major early source of the antiviral IFN- $\gamma$ at the primary site of various viral infection, including IAV (170). Interestingly, IFN- $\gamma$ was found to suppress ILC2 activity and reduce IL5 production which exacerbates disease severity during influenza $\mathrm{A}(\mathrm{H} 1 \mathrm{~N} 1)$ pdm09 infection (171). This data may highlight a link between ILC1 and ILC2 and suggesting ILC1 can suppress ILC2 activity via IFN- $\gamma$ production during IAV infection.

With ILCs finally identified, functions of these cells and their role in immune response to tumors and pathogen infections have been massively investigated in recent years. Type I IFNs, prostaglandin $\mathrm{I}_{2}$, corticosteroids, and testosterone have been reported to suppress ILC2 activity $(172,173)$. In addition to IL-33, the epithelial cytokines IL-25, thymic stromal lymphopoietin, as well as the lipid mediator prostaglandin $\mathrm{D}_{2}$ were found to activate ILC2 (173). The therapeutic potential of these ILC2 activators and suppressors is yet to be deduced. With more and more studies demonstrating the involvement of ILC in IAV infection, the interplay between different ILC subtypes in IAV infection would, therefore, be an interesting area to explore and modulate the ILC activity may be a future approach to combat IAV infection.

\section{Reactive Oxygen Species}

Reactive oxygen species, generated by specialized enzymes such as NADPH oxidases, are released during IAV infection (174). The NADPH oxidase family consists of enzymes containing different catalytic subunit named Nox1-5 and dual oxidase (Duox) 1 and 2 . ROS have been reported to display both beneficial (limiting viral replication) and detrimental (promoting ALI) effects in the course of IAV infection. Interestingly, the protective or destructive effect of ROS is dependent on the enzyme of which the ROS is generated (174).

Dual oxidase 1 and 2 are found to be host-protective $(174,175)$. In vitro, ROS generated by nuclear Duox indirectly regulates the splicing of IAV mRNAs via the nuclear speckle-associated splicing complex (175). In addition to altering viral mRNA splicing, ROS generated by Doux 2 has been attributed to the production of IFN- $\lambda$, an important anti-IAV IFN. In response to IAV infection, increased viral mRNA replication was observed when Duox2 was silenced in vitro (176). Increased viral replication was also observed in mice with Doux silenced (175), further depicting the protective role of Doux in IAV infection.

Unlike Doux, Nox2 activation could be harmful to host. IAV infection was reported to induce Nox2-dependent endosomal ROS production (177). ROS could target the conserved Cys98 on Toll-like receptor (TLR) 7, and inhibit TLR7-mediated type I IFN expression during a mild IAV $\mathrm{H} 3 \mathrm{~N} 2$ infection in vivo (177). IAV-infected mice treated with specific Nox2 inhibitor, cholestanol-conjugated gp91ds-TAT, were found to have reduction in endosomal ROS production, restored TLR7 activity, and displayed a decreased viral load (177). In addition to Nox2, Nox4dependent ROS production has also been reported to activate MAPK/ERK signaling (178), enhancing the export of vRNP complex, thus increasing viral replication (see Targeting the Raf/ MEK/ERK Pathway). Nox4 knockdown resulted in a reduction of viral replication in vitro (178).

Targeting the different NADPH oxidase isoforms, instead of scavenging ROS should be considered as the therapeutic approach for IAV infection, as Doux-mediated ROS production is beneficial $(175,176)$, while Nox 2 and Nox4 are harmful during IAV infections $(177,178)$. Finally, NS1 (not to be confused with IAV NS1 protein) has been demonstrated to be a Nox inhibitor, which could inhibit the activity of Nox1, Nox2, and Nox4. A study demonstrated that NS1 suppresses IAV-induced Nox2 and significantly inhibits IAV virus replication (179). Besides cholestanolconjugated gp91ds-TAT and NS1 aforementioned, apocynin, a phagocytic Nox2 inhibitor as well as ROS scavenger (180-182), has been demonstrated to ameliorate hyper upregulation of cytokines induced by IAV infection through SOCS1 and SOCS3 in vitro (154) and reduce peri-bronchial inflammation and viral titer in vivo (183). Interestingly, ebselen, another Nox2 inhibitor and glutathione peroxidase mimetic, could reduce inflammatory status measured in bronchoalveolar lavage fluid (BALF) of mice pre-exposed to cigarette smoke and subsequently infected with IAV (184). Taken together, these reports highlight the potential use of NADPH oxidases inhibitors and ROS scavengers to treat IAV infections.

\section{Soluble Mediators and Receptor-Based Immunomodulation}

Dysregulated cytokine production has been associated with the elevated mortality rate observed in severe IAV infections $(185,186)$. As such, the immunomodulation of cytokines are regarded as promising therapeutic tactics. Recent advancements developed with this approach will be highlighted in the following section.

\section{Tumor Necrosis Factor}

Tumor necrosis factor has two main functions during viral infection-it activates NF- $\mathrm{KB}$, inducing the expression of cytokines responsible for the host immune response; and induces apoptosis through activation of a signaling cascade involving TRADD, FADD, and caspase 3, 7, 8, and 10 (187-189). TNF is known to be highly upregulated in IAV-infected hosts, especially in hosts infected with highly pathogenic IAV $(153,190)$. However, it is both protective and counter-protective functions associated with TNF that makes it a target in the treatment of IAV.

The protective role of TNF is observed during infection by low pathogenic IAV, where extrinsically derived TNF is responsible for attenuating tissue-damaging $\mathrm{CD}^{+}{ }^{+} \mathrm{T}$-cell response (191). In addition to recruiting monocytic cells to the infection site, $\mathrm{CD}^{+}$ T-cells response was observed to deteriorate lung pathology (192) and damage healthy, non-infected lung epithelial cells (193) upon IAV infection. Furthermore, TNF deficiency has been associated with an increased detection of IL-15 and IL-6 in BALF (192), 
which promote the survival of and proliferation of $\mathrm{CD}^{+} \mathrm{T}$-cells (194, 195) and subsequent tissue damage. Exacerbated lung pathology caused by the upregulation of the monocyte chemoattractant protein-1 was observed in $\mathrm{TNF}^{-/-}$mice infected with sub-lethal dose of IAV (196). In addition, decreased CD8 ${ }^{+}$T-cell contraction due to enhanced expression of the anti-apoptotic protein Bcl-2 was observed in sub-lethally IAV-infected TNFdeficient mice when compared to WT mice (192). As a whole, there is substantial evidence supporting the protective role of TNF in IAV infection.

On the other hand, the correlation of TNF with pulmonary edema has been well-documented (197). TNF has been observed to stimulate the expression of CXCL2 in alveolar epithelial cells in a transgenic mice model resembling extensive IAV infection in lung tissue, causing alveolar damage, lung edema, and hemorrhage (198). In addition to lung edema, TNF has also been reported to correlate with IAV-associated encephalopathy (199, 200). However, it is notable that despite IAV-associated encephalopathy, direct invasion of the central nervous system is rare (201), suggesting that IAV-associated encephalopathy could instead be a result of peripheral infection. Furthermore, TNF has been shown to increase the permeability of the blood-brain barrier (BBB) (202, 203), contributing to neural damage (204). These studies further support an anti-TNF approach as a potential therapy for severe IAV infection.

At present, etanercept, an anti-TNF drug administered in the treatment of rheumatoid arthritis, is the only TNF inhibitor (or even TNF directed treatment) tested for IAV treatment. Etanercept has been shown to protect against the in vivo lethal infection of mice with a highly virulent, mouse-adapted IAV strain (205), with observations made of an increased survival rate with decreased morbidity, expression of the proinflammatory cytokine IL-6, lung injury, and edema (205).

\section{IL-6 and IL-27}

The protective role of IL- 6 was demonstrated in mice challenged with sub-lethal IAV infection. IL-6-deficient mice displayed exacerbated pulmonary damage $(206,207)$ and lung injury due to an observed decline in the survival of alveolar type II cells and alveolar epithelial cells (207). IAV suppresses the anti-apoptotic Mcl-1 and $\mathrm{Bcl}-\mathrm{X}_{\mathrm{L}}$ expression, causing cell death of neutrophils which are critical in viral clearance (206). Addition of IL-6 restored the expression of Mcl-1 and Bcl- $\mathrm{X}_{\mathrm{L}}$ in vitro and is considered as the underlying mechanism for the observed survival advantage of WT mice over $I L-6$ knockout mice during mild IAV infection.

IL- 6 has also been shown to induce the proliferation of lung IL- $10^{+}$regulatory $\mathrm{T}$ cells and $\mathrm{IL}-27$, which act to limit excessive proliferation of $\mathrm{CD}^{+} \mathrm{T}$-cells and subsequent $\mathrm{CD}^{+}$-inflicted damage. This would hence prevent the tissue damage observed in lung immunopathology (208).

Despite the apparent protective role of IL-6, high levels of IL-6 in serum or cerebrospinal fluid have been reported in severe neurologically complicated IAV cases, with IL-6 used as a marker for prognosis $(199-201,209,210)$. The role of IL-6 in regulation of BBB permeability was reported (211), with potentially detrimental neurological complications. As such, the suppression of hyper-induced IL-6 as a form of therapy in severe IAV infection should be considered. One such option is the anti-IL6 antibodybased drug tocilizumab, which is currently administered clinically for the treatment of rheumatoid arthritis. However, study on the usage of this drug to treat hyper upregulation of IL-6 due to severe IAV infection has yet to be conducted. On the other hand, in a case of H1N1 virus-induced ARDS, the use of an extracorporeal cytokine hemoadsorption device to remove cytokines including TNF and IL-6 from the bloodstream (212) has showed beneficial to the patient (213). More research is required to confirm whether the removal or neutralization of IL- 6 could be a potential therapy for severe IAV infections.

The activation of $\mathrm{CD} 8^{+} \mathrm{T}$-cell is crucial for viral clearance. It should, however, be tightly regulated to limit $\mathrm{CD} 8^{+} \mathrm{T}$-cell inflicted host cell damage. IL-6 mediates IL-27 induction (208). IL-27 acts to suppress CD8 ${ }^{+}$T-cells and reduce morbidity through IL-10 and regulatory T-cells (208). Much like other immunomodulatory approaches, the timing for applying IL-27 should be carefully assessed. Compared to placebo-treated IAVinfected group, early administration of IL-27 to IAV-infected mice in fact led to poorer viral clearance, increased morbidity, and deteriorated lung histopathology, while IL-27 administration during the recovery phase (5-10 days post-infection) accelerated recovery and improve lung immunopathology (214). Notably, IL-27 could also suppress Th17 responses and increases susceptibility to secondary $S$. aureus infection (215). Therefore, co-administration of antibiotics should be considered when utilizing IL-27 as potential IAV treatment.

\section{Type I and III Interferons}

Both type I and III IFNs have antiviral properties, with viruses counteract IFNs to gain an advantage for their propagation. The IAV viral protein NS1 inhibits the production of IFNs by antagonizing IRF-3, a key transcriptional factor for IFNs. This prevents the processing of cellular pre-mRNAs (including those for IFNs) and directly interacts with retinoic acid-inducible gene (RIG)-I receptors, which are critical in innate sensing, to suppress IFN production during infection $(216,217)$. In addition to inhibiting IFN expression, the induction of SOCS3 inhibits IFNs signaling by suppressing cytokine signaling has been documented (155).

The recognition of $5^{\prime}$ triphosphate on viral RNA by RIG-I receptor is shown to induce the expression of SOCS3, which in turn represses type I IFNs expression (155). Due to IFNs being a key contributor to antiviral immune response, an impairment of type I or III IFN production may cause the escalation of otherwise mildly pathogenic IAV infection into a life-threatening one (218).

While type I IFN has been demonstrated to inhibit IAV replication in vitro (219); the in vivo administration of type I IFN in animal models only displayed effectiveness in a prophylactic capacity. A lowered viral titer was detected in the nasal wash of test animals. However, host susceptibility to IAV infection remained unchanged (219). Notably, this protective effect is only conferred by an optimal dose of type I IFN of low to moderate amounts (10-100 units per mice daily); with higher dosages (1,000-10,000 units per mice daily) shown to increase morbidity (220). In addition, clinical trials demonstrated that prophylactic administration of type I IFN reduced disease severity and lowered susceptibility to IAV in males and participants aged 50 or above (221). 
Despite relatively successful results seen in the prophylactic use of IFNs, its therapeutic use is of greater clinical relevance. Mice treated with type I IFN post-IAV infection showed a successful reduction in lung IAV titer but displayed increased morbidity and mortality in comparison to vehicle-treated mice (222). A possible explanation for this phenomenon is the induction of excessive inflammatory response and TRAIL-DR5-mediated epithelial cell death by type I IFN (223), which accounts for the observed lung pathology in IAV-infected animals treated with type I IFN (224). In addition, downregulation of $\gamma \delta$ T-cells by type I IFN has been correlated with increased susceptibility to secondary S. pneumoniae infection (225), further arguing against the potential use of type I IFNs for the treatment of IAV infection.

In comparison to type I IFNs, the administration of type III IFNs may provide advantages in the control of IAV replication $(176,222,224)$ without the risk of previously reported type I IFNs-mediated immunopathologic side-effects $(222,224,226)$. However, a recent study aiming to stimulate IFNs signaling through the systematic administration of RIG-I ligand post-IAV infection demonstrated that type I, but not type III IFNs signaling is important in conferring protection during fatal IAV infection in vivo (227). Though, this study did not measure the production of type I and III IFNs as well as any changes in viral load with respect to Ifnar or Ifnlr knockout. In addition, while human immune cells are not primary targets in IAV infection, they could be susceptible to IAV and become efficient host cells for virus replication. They are reported to possess a subpar response to type III IFNs (222); leading to the preliminary conclusion that solely using type III IFN as treatment may not be feasible. As such, reports suggesting the use of type III IFNs over type I IFNs as a front-line therapeutic agent to counter IAV infections may require further investigation.

\section{Prostaglandin $\mathrm{E}_{2}$}

The inhibition of COX-2 by selective inhibitors, nimesulide and celecoxib, was previously demonstrated to suppress the hyper upregulation of pro-inflammatory cytokines induced by highly pathogenic avian IAV (228-230). In addition, the use of zanamivir in tandem with a specific COX-2 inhibitor was shown to increase the survival rate of mice lethally infected with avian H7N9 IAV, when compared to mice treated solely with zanamivir (229).

Activated COX-2 regulates downstream prostaglandin production. One such example is $\mathrm{PGE}_{2}$, a major type of prostaglandin recently demonstrated to play an important role during IAV infection. $\mathrm{PGE}_{2}$ was significantly upregulated in response to IAV infection, leading to the inhibition of antiviral type I IFN production in macrophages and the subsequent increase in virus replication (231). The use of chemicals AH6809 and GW627368X to antagonize $\mathrm{PGE}_{2}$ downstream signaling molecules EP2 and EP4 respectively, was shown to induce antiviral type I IFN production. The in vivo treatment of mice lethally challenged IAV with both EP2 and EP4 antagonists significantly improved the survival rate.

A recent study demonstrated the ability of a modified TCM decoction to reduce $\mathrm{PEG}_{2}$ production and subsequent morbidity in mice lethally challenged with IAV. Improved lung pathology was observed (232). The long history of clinical TCM use supports the clinical feasibility of $\mathrm{PEG}_{2}$ inhibition as an option to treat severe IAV infections.

\section{Toll-Like Receptors (TLRs)}

Pattern recognition receptors on host cells sense specific PAMPs present on the viral surface or generated during replication. PRRs can be broadly divided into two classes by their function or location. When defined by location, PRRs are classified into 3 groups-membrane-bound (TLRs and C-type lectin receptors), cytosolic (RIG-I-like and NOD-like receptors), and secreted (collectins and pentraxins) (233).

Significant research has been conducted on PRRs with regards to IAV infection. TLRs and RIG-I receptors have been extensively studied for their major roles in eliciting host immune responses (cytokine and IFN expression) during IAV infection (234-236). RIG-I receptors have been investigated for their functional relevance to IAV infection and targeting these receptors as a form of IAV treatment has been extensively reviewed (237-239). This section will cover recent research on TLRs and the targeting of different TLRs to treat IAV infection.

Humans have been identified to express TLR1-10, while mice have been identified to express functional TLR1-9 as well as TLR11-13 (240). Most TLRs-with the exception of TLR3utilize MyD88 as an adaptor protein during signal transduction. TLR3 utilizes TRIF as an adaptor. TLR4 is known for its ability to utilize either MyD88 or TRIF, with the choice of adaptor dependent on its sub-cellular location (241). Different TLRs, such as TLR3, 7, and 8 (240) as well as TLR2, TLR4, and most recently TLR10 (235), have been revealed to play a role in the orchestration of host immune responses contributing to IAV pathogenesis.

With TLR10 being an exception (242-244), TLR activation largely causes the release of pro-inflammatory cytokines, with hypercytokinemia leading to ALI as a major cause of mortality in severe IAV infections. In addition to dysregulated cytokine release, excessive production of ROS has been associated with ALI development. In fact, lung injury during severe pulmonary infections, such as IAV and SARS, could be caused by oxidative stress (245). IAV infection activates NADPH oxidase that subsequently produces oxidized PAPC, an endogenous phospholipid. The oxidized PAPC serves as an agonist for TLR4, activating a TLR4-TRIF-TRAF6-NF- $\mathrm{KB}$ signaling cascade to eventually trigger the release of IL-6, ultimately inducing the onset of ALI. In addition to oxidized PAPC, the induction of endogenous protein S100A9 upon intracellular PRR DDX21 recognition of IAV subsequently induces the activation of TLR4, further contributing to IAV-induced mortality (246). Since TLR4 has been proven to be important in ALI induction (and hence IAV-related mortality), manipulating the stimulation and antagonism of TLR4 could potentially reduce the severity of IAV infections.

Eritoran (E5564) is a specific TLR4 antagonist initially purposed for the treatment of sepsis, but a failed a phase III clinical trial due to improved patient care in the placebo group prevented its eventual use in sepsis treatment (247). In vivo administration of eritoran in mice lethally infected with IAV resulted in improved clinical score, lung pathology results, and reduced viral titer. Delayed administration of eritoran, at day 6 after infection beyond the recommended therapeutic time window (within $48 \mathrm{~h}$ after 
the first display of clinical symptom) for use of oseltamivir (248), also demonstrated a significant benefit to infected mice compared to non-treated group, suggesting a prolonged therapeutic time window for IAV treatment when compared to mainstay antiviral drug treatment. A newer and structurally simpler specific TLR4 antagonist, FP7 (249), alongside a newly developed decoy peptide 2R9 that has been shown to disrupt TLR2, 4, 7, and 9 signaling via TIRAP, has been shown to protect mice from lethal IAV infection (250). These results support the potential use of TLR4 antagonism as a means to treat severe IAV infection.

The suppression of other TLR signaling pathways-such as blocking TLR2-mediated signaling through the use of an antiTLR2 antibody, significantly protected against lethality when administered on day 2 and 4 post-IAV infection (251).

A study also demonstrated that H5N1-infected TLR3 knockout mice had better survival than H5N1-infected wild-type mice, which is evident through the significantly faster regaining of body weight post-infection, lower viral titer in the lung, and fewer pathological changes in the lung (252).

An increasing number of TLR antagonists are now under development $(253,254)$, alongside several other agents also shown to have effects on TLRs. Polysaccharides isolated from
R. isatidis, a traditional Chinese medicinal herb used to treat IAV infection, have recently been shown to inhibit pro-inflammatory cytokines such as IL- 6 and CCL-5 in vitro by down-regulating upstream TLR3 expression (255). MENK, an endogenous protein expressed in the adrenal medulla, was shown to both prophylactically and therapeutically increase the survival rate while reducing viral-caused lung pathology and viral titer in mice lethally challenged with IAV (256). This was determined to be caused by the downregulation of TLR7. These results suggest the potential of down-regulating TLR expression in the treatment of IAV infection.

The above-mentioned data suggest modulation of TLR signaling or expression as a promising approach in treating severe influenza disease and deserves immediate investigation. Table 2 summarizes new immunomodulatory approaches to combat IAV infections.

\section{MODULATION OF METABOLISM}

It is well documented that patients with diabetes mellitus have a greater tendency to develop severe IAV infection than healthy patients (257). Hyperglycemia increases susceptibility of the

TABLE 2 | New immunomodulatory approaches to treat influenza A virus (IAV) infection.

\begin{tabular}{|c|c|c|c|}
\hline $\begin{array}{l}\text { Potential target/ } \\
\text { approach }\end{array}$ & Possible intervention & Effect & Reference \\
\hline Histones & Anti-histone antibodies & $\begin{array}{l}\text { Prevents lung inflammation and } \\
\text { damage induced by histones }\end{array}$ & Ashar et al. (161) \\
\hline NETosis & $\begin{array}{l}\text { a. Cl-amidine } \\
\text { b. Tetrahydroisoquinolines (both tested on } \\
\text { NETosis, effect on IAV yet to be determined) }\end{array}$ & Prevents lung injury mediated by NET & $\begin{array}{l}\text { a. Kusunoki et al. (164) } \\
\text { b. Martinez et al. (163) }\end{array}$ \\
\hline ILC2 & To be determined & Promotes airway epithelium repair & Califano et al. (171) \\
\hline Nox2 & $\begin{array}{l}\text { a. Cholestanol-conjugated gp91ds-TAT } \\
\text { b. Apocynin [also as reactive oxygen species } \\
\text { (ROS) scavenger] } \\
\text { c. Ebselen (also as ROS scavenger and glutathione } \\
\text { peroxidase mimetic) }\end{array}$ & Inhibits Nox2 activity & $\begin{array}{l}\text { a. To et al. (177) } \\
\text { b. Ye et al. (154) } \\
\text { c. Oostwoud et al. (184) }\end{array}$ \\
\hline $\begin{array}{l}\text { Tumor necrosis } \\
\text { factor (TNF) }\end{array}$ & Etanercept & Prevents TNF-mediated lung injury and edema & Shi et al. (205) \\
\hline IL-6 & Administration of IL-6 & $\begin{array}{l}\text { Inhibits cell death of neutrophils; limits } \\
\text { CD8 }{ }^{+} \text {T-cell-induced lung injury }\end{array}$ & Dienz et al. (206); Pyle et al. (208) \\
\hline IL-27 & $\begin{array}{l}\text { Administration of IL-27 at recovery phase } \\
\text { (5-10 days post-infection) }\end{array}$ & Promotes recovery and improves lung immunopathology & Liu et al. (214) \\
\hline Type III IFN & Administration of type III IFN & Controls IAV replication by type III IFN signaling pathways & $\begin{array}{l}\text { Davidson et al. (222); } \\
\text { Kim et al. (224) }\end{array}$ \\
\hline $\mathrm{PGE}_{2}$ signaling & $\begin{array}{l}\text { a. AH6809 (EP2 antagonist) } \\
\text { b. GW627368X (EP4 antagonist) }\end{array}$ & $\begin{array}{l}\text { Restores type I IFNs induction which are suppressed by } \\
\mathrm{PGE}_{2} \text { in macrophages }\end{array}$ & Coulombe et al. (231) \\
\hline TLR4 signaling & TLR4 antagonists (a. Eritoran and b. FP7) & Ameliorates TLR4-mediated lung injury & $\begin{array}{l}\text { a. Shirey et al. (248) } \\
\text { b. Perrin-Cocon et al. (249) }\end{array}$ \\
\hline TIRAP antagonism & Peptide 2R9 & Inhibits multiple TLR signaling & Piao et al. (250) \\
\hline TLR2 signaling & Anti-TLR2 antibody & Inhibits TLR2 signaling mediated lethality & Shirey et al. (251) \\
\hline TLR3 signaling & Polysaccharides isolated from $R$. isatidis & $\begin{array}{l}\text { Down regulates TLR3 expression to inhibit } \\
\text { hypercytokinemia }\end{array}$ & Li et al. (255) \\
\hline TLR7 signaling & MENK & $\begin{array}{l}\text { Down regulates TLR7 expression and reduces lung } \\
\text { pathology }\end{array}$ & Tian et al. (256) \\
\hline
\end{tabular}


host to IAV infection via viral uptake, through the promotion of V-ATPase assembly (258) and immunosuppression (257). In addition, viruses rely on host metabolism to perform essential functions during replication (259-262). These processes exert a large energy demand on the host within a very short period of time (263); energy of which is supplied by and is dependent on host metabolism. IAV viruses have been reported to modify the metabolic state of the host. For example, increased c-Myc-dependent glycolysis and glutaminolysis has been demonstrated in infected cells (264). The changes in glucose and glutamine metabolism were reversed upon the addition of BEZ235, which inhibited the IAV-mediated c-Myc induction. Administration of BEZ235 2 days prior to infection and up to 4 days post-infection was shown to decrease lung viral titer and improve the survival rate in IAV-infected mice. Small molecules such as clotrimazole and $\alpha$-mangostin that target lipid metabolism have also been demonstrated to suppress IAV replication in vitro (264).

In addition to being important for generating energy and biosynthesis, recent research demonstrates that cellular metabolism affects immune cell function. Dysregulated immune responses observed in many diseases are associated with specific metabolic configurations. Viruses, influenza inclusive (265), were found to induce drastic alterations in metabolic levels and programs (263). Macrophages in infected hosts were observed to have marked differences in the Krebs cycle, a key metabolic pathway. This is of significance due to the role of macrophages, which are immune cells critical in the pathogenesis of many inflammatory diseases $(263,265,266)$.

In activated macrophages, succinate, a Krebs cycle intermediate, was found to possess inflammatory signal. Accumulation of succinate generates ROS, leading to subsequent activation of hypoxia-inducible factor $1 \alpha$ and the induction of cytokines such as IL-1 $\beta$ (267). A recent study identified the ability of itaconate, another Krebs cycle-derived metabolite, to block the production of inflammatory factors. This prevented inflammation, protecting mice from lethal levels of inflammation that can occur during infection (268). This data suggest the critical roles of Krebs cycle intermediates in regulating cytokine profiles and inflammation. Metabolites generated by innate immune cells in distinct configurations could have different roles beyond that of bioenergetics, with functions in signaling regulation, transcription, and orchestrating innate immune responses.

Despite the lack of research conducted thus far on the application of immunometabolic approaches to influenza treatment, the prospect of manipulating immune responses by modulating immune cell metabolic state is promising. Further research should focus on the identification of metabolites for modulation of immune cell function with substantial improvement of therapeutic strategies to treat IAV disease.

Latest advancements in high-throughput technologies, e.g., metabolomics is a useful approach to systematically investigate the changes of metabolic mechanisms during IAV infections. Identification of important metabolites involved during IAV infection should be a new approach by modulating the host metabolism for interventions.

\section{CONCLUDING REMARKS}

Multiple host-based intervention strategies against influenza have been developed or are under development. While approaches targeting host machinery required for virus replication seem to be promising thus far, additional research is needed to determine the effect of modulating host immune response on influenza treatment. This is increasingly important, since targeted host factors may play distinct roles in response to infection by different influenza viral strains (252), making the management of influenza through solely targeting a single specific host factor is difficult.

Host-based interventions offer obvious advantages over conventional antivirals, such as a higher barrier to drug resistance $(73,83,107)$ due to greater genetic stability of host factors than the mutation-prone nature of viral components. In addition, administration feasibility is a key factor to consider the usage of drugs. The mainstays of antivirals for IAV infections, the NA inhibitors, and M2 blockers, are recommended to be administered within $48 \mathrm{~h}$ of symptom onset for optimal antiviral activity. This short treatment window may not be fully fulfilled in a clinical setting. Novel host-based interventions were reported to have therapeutic time windows longer than this conventional timeframe $(96,109,214,251)$, even up to 6 days post-infection (248), providing a clear clinical advantage over NA inhibitors and M2 blockers. In addition, hypercytokinemia and ARDS could contribute to disease severity and mortality in instances of severe influenza infection, with virustargeting antivirals providing little to no alleviation of such complications.

Since host immune response is indispensable in host defense against invading pathogens, the use of immune-modulators to suppress detrimental effects while retaining beneficial protection of the host remains challenging. The timing and dosage of medication administration would be critical in determining the drug effectiveness in influenza treatment.

Targeting virus-induced metabolic changes to restore host normal metabolism may be a new direction to combat influenza disease. Further research in the immunometabolism field, alongside studies on modulating immune response to infectious disease by altering host metabolic processes; would create a new direction for future research and is expected to yield significant discoveries that may provide new therapeutic options in the treatment of IAV infections.

\section{AUTHOR CONTRIBUTIONS}

SMYL conceptualized the work. IL and ASMS drafted some review sections and TFY and SMYL wrote the manuscript.

\section{FUNDING}

Funding was provided by Research Grants Council of Hong Kong, General Research Fund \#17111714, and Theme-based Research Scheme \#T11-705/14-N; Health and Medical Research Fund \#12111822 and 14130662; and Procore France/Hong Kong Joint Research Scheme \#F-HKU708/16T. 


\section{REFERENCES}

1. Gurav YK, Chadha MS, Tandale BV, Potdar VA, Pawar SD, Shil P, et al. Influenza $\mathrm{A}(\mathrm{H} 1 \mathrm{~N} 1)$ pdm09 outbreak detected in inter-seasonal months during the surveillance of influenza-like illness in Pune, India, 2012-2015. Epidemiol Infect (2017) 145(9):1898-909. doi:10.1017/S0950268817000553

2. Hui DSC, Lee N, Chan PKS. Avian influenza A (H7N9) virus infections in humans across five epidemics in mainland China, 2013-2017. J Thorac Dis (2017) 9(12):4808-11. doi:10.21037/jtd.2017.11.17

3. Olafsdottir TA, Alexandersson KF, Sveinbjornsson G, Lapini G, Palladino L, Montomoli E, et al. Age and influenza-specific pre-vaccination antibodies strongly affect influenza vaccine responses in the Icelandic population whereas disease and medication have small effects. Front Immunol (2017) 8:1872. doi:10.3389/fimmu.2017.01872

4. Moscona A. Global transmission of oseltamivir-resistant influenza. $N$ Engl J Med (2009) 360(10):953-6. doi:10.1056/NEJMp0900648

5. Takashita E, Fujisaki S, Shirakura M, Nakamura K, Kishida N, Kuwahara T, et al. Influenza $\mathrm{A}(\mathrm{H} 1 \mathrm{~N} 1)$ pdm09 virus exhibiting enhanced cross-resistance to oseltamivir and peramivir due to a dual H275Y/G147R substitution, Japan, March 2016. Euro Surveill (2016) 21(24):30258. doi:10.2807/1560-7917. ES.2016.21.24.30258

6. Centers for Disease Control and Prevention. High levels of adamantane resistance among influenza A (H3N2) viruses and interim guidelines for use of antiviral agents - United States, 2005-06 influenza season. MMWR Morb Mortal Wkly Rep (2006) 55(2):44-6.

7. Schaduangrat N, Phanich J, Rungrotmongkol T, Lerdsamran H, Puthavathana P, Ubol S. The significance of naturally occurring neuraminidase quasispecies of H5N1 avian influenza virus on resistance to oseltamivir: a point of concern. J Gen Virol (2016) 97(6):1311-23. doi:10.1099/jgv.0.000444

8. Lina B, Boucher C, Osterhaus A, Monto AS, Schutten M, Whitley RJ, et al. Five years of monitoring for the emergence of oseltamivir resistance in patients with influenza A infections in the Influenza Resistance Information Study. Influenza Other Respi Viruses (2018) 12(2):267-78. doi:10.1111/irv. 12534

9. Tandel K, Sharma S, Dash PK, Parida M. Oseltamivir-resistant influenza $\mathrm{A}(\mathrm{H} 1 \mathrm{~N} 1) \mathrm{pdm} 09$ virus associated with high case fatality, India 2015. J Med Virol (2018) 90(5):836-43. doi:10.1002/jmv.25013

10. Szretter KJ, Gangappa S, Lu X, Smith C, Shieh WJ, Zaki SR, et al. Role of host cytokine responses in the pathogenesis of avian $\mathrm{H} 5 \mathrm{~N} 1$ influenza viruses in mice. J Virol (2007) 81(6):2736-44. doi:10.1128/JVI.02336-06

11. Short KR, Veeris R, Leijten LM, van den Brand JM, Jong VL, Stittelaar K, et al. Proinflammatory cytokine responses in extra-respiratory tissues during severe influenza. J Infect Dis (2017) 216(7):829-33. doi:10.1093/infdis/ jix281

12. Chi Y, Zhu Y, Wen T, Cui L, Ge Y, Jiao Y, et al. Cytokine and chemokine levels in patients infected with the novel avian influenza A (H7N9) virus in China. J Infect Dis (2013) 208(12):1962-7. doi:10.1093/infdis/jit440

13. Lee SM, Yen HL. Targeting the host or the virus: current and novel concepts for antiviral approaches against influenza virus infection. Antiviral Res (2012) 96(3):391-404. doi:10.1016/j.antiviral.2012.09.013

14. Konig R, Stertz S, Zhou Y, Inoue A, Hoffmann HH, Bhattacharyya S, et al. Human host factors required for influenza virus replication. Nature (2010) 463(7282):813-7. doi:10.1038/nature08699

15. Karlas A, Machuy N, Shin Y, Pleissner KP, Artarini A, Heuer D, et al. Genome-wide RNAi screen identifies human host factors crucial for influenza virus replication. Nature (2010) 463(7282):818-22. doi:10.1038/ nature 08760

16. Edinger TO, Pohl MO, Stertz S. Entry of influenza A virus: host factors and antiviral targets. J Gen Virol (2014) 95(Pt 2):263-77. doi:10.1099/vir.0. 059477-0

17. Luo M. Influenza virus entry. Adv Exp Med Biol (2012) 726:201-21. doi:10.1007/978-1-4614-0980-9_9

18. Rust MJ, Lakadamyali M, Zhang F, Zhuang X. Assembly of endocytic machinery around individual influenza viruses during viral entry. Nat Struct Mol Biol (2004) 11(6):567-73. doi:10.1038/nsmb769

19. de Vries E, Tscherne DM, Wienholts MJ, Cobos-Jimenez V, Scholte F, Garcia-Sastre A, et al. Dissection of the influenza A virus endocytic routes reveals macropinocytosis as an alternative entry pathway. PLoS Pathog (2011) 7(3):e1001329. doi:10.1371/journal.ppat.1001329
20. Yasuda S, Morishita S, Fujita A, Nanao T, Wada N, Waguri S, et al. Mon1Ccz1 activates Rab7 only on late endosomes and dissociates from the lysosome in mammalian cells. J Cell Sci (2016) 129(2):329-40. doi:10.1242/jcs. 178095

21. Rossman JS, Leser GP, Lamb RA. Filamentous influenza virus enters cells via macropinocytosis. J Virol (2012) 86(20):10950-60. doi:10.1128/JVI.05992-11

22. Huotari J, Helenius A. Endosome maturation. EMBO J (2011) 30(17): 3481-500. doi:10.1038/emboj.2011.286

23. Hu YB, Dammer EB, Ren RJ, Wang G. The endosomal-lysosomal system: from acidification and cargo sorting to neurodegeneration. Transl Neurodegener (2015) 4:18. doi:10.1186/s40035-015-0041-1

24. Li S, Sieben C, Ludwig K, Hofer CT, Chiantia S, Herrmann A, et al. pH-Controlled two-step uncoating of influenza virus. Biophys J (2014) 106(7):1447-56. doi:10.1016/j.bpj.2014.02.018

25. Steinhauer DA. Role of hemagglutinin cleavage for the pathogenicity of influenza virus. Virology (1999) 258(1):1-20. doi:10.1006/viro.1999.9716

26. Zhirnov OP, Ikizler MR, Wright PF. Cleavage of influenza a virus hemagglutinin in human respiratory epithelium is cell associated and sensitive to exogenous antiproteases. J Virol (2002) 76(17):8682-9. doi:10.1128/JVI.76. 17.8682-8689.2002

27. Pielak RM, Chou JJ. Influenza M2 proton channels. Biochim Biophys Acta (2011) 1808(2):522-9. doi:10.1016/j.bbamem.2010.04.015

28. Ye Z, Liu T, Offringa DP, McInnis J, Levandowski RA. Association of influenza virus matrix protein with ribonucleoproteins. J Virol (1999) 73(9):7467-73.

29. Byrd-Leotis L, Galloway SE, Agbogu E, Steinhauer DA. Influenza hemagglutinin (HA) stem region mutations that stabilize or destabilize the structure of multiple HA subtypes. J Virol (2015) 89(8):4504-16. doi:10.1128/ JVI.00057-15

30. Lu X, Shi Y, Gao F, Xiao H, Wang M, Qi J, et al. Insights into avian influenza virus pathogenicity: the hemagglutinin precursor HA0 of subtype H16 has an alpha-helix structure in its cleavage site with inefficient HA1/HA2 cleavage. J Virol (2012) 86(23):12861-70. doi:10.1128/JVI.01606-12

31. Bottcher E, Matrosovich T, Beyerle M, Klenk HD, Garten W, Matrosovich M. Proteolytic activation of influenza viruses by serine proteases TMPRSS2 and HAT from human airway epithelium. J Virol (2006) 80(19):9896-8. doi:10.1128/JVI.01118-06

32. Xin Y, Liu L, Chen B, Zhang L, Tong Y. Affinity purification of aprotinin from bovine lung. J Sep Sci (2015) 38(9):1441-8. doi:10.1002/jssc.201401188

33. Swaminathan M, Stuart M, Hughes GC, Jaggers J, Hill SE, Milano CA, et al. Institutional response to FDA warning on aprotinin and impact on outcomes. HSR Proc Intensive Care Cardiovasc Anesth (2009) 1(1):30-6.

34. Ovcharenko AV, Zhirnov OP. Aprotinin aerosol treatment of influenza and paramyxovirus bronchopneumonia of mice. Antiviral Res (1994) 23(2):107-18. doi:10.1016/0166-3542(94)90038-8

35. Yamaya M, Shimotai Y, Hatachi Y, Lusamba Kalonji N, Tando Y, Kitajima Y, et al. The serine protease inhibitor camostat inhibits influenza virus replication and cytokine production in primary cultures of human tracheal epithelial cells. Pulm Pharmacol Ther (2015) 33:66-74. doi:10.1016/j.pupt.2015.07.001

36. Zhirnov OP, Klenk HD, Wright PF. Aprotinin and similar protease inhibitors as drugs against influenza. Antiviral Res (2011) 92(1):27-36. doi:10.1016/j. antiviral.2011.07.014

37. Lee MG, Kim KH, Park KY, Kim JS. Evaluation of anti-influenza effects of camostat in mice infected with non-adapted human influenza viruses. Arch Virol (1996) 141(10):1979-89. doi:10.1007/BF01718208

38. Ota S, Hara Y, Kanoh S, Shinoda M, Kawano S, Fujikura Y, et al. Acute eosinophilic pneumonia caused by camostat mesilate: the first case report. Respir Med Case Rep (2016) 19:21-3. doi:10.1016/j.rmcr.2016.06.005

39. Shen LW, Mao HJ, Wu YL, Tanaka Y, Zhang W. TMPRSS2: a potential target for treatment of influenza virus and coronavirus infections. Biochimie (2017) 142:1-10. doi:10.1016/j.biochi.2017.07.016

40. Stieneke-Grober A, Vey M, Angliker H, Shaw E, Thomas G, Roberts C, et al. Influenza virus hemagglutinin with multibasic cleavage site is activated by furin, a subtilisin-like endoprotease. EMBO J (1992) 11(7):2407-14.

41. Bahgat MM, Blazejewska P, Schughart K. Inhibition of lung serine proteases in mice: a potentially new approach to control influenza infection. Virol J (2011) 8:27. doi:10.1186/1743-422X-8-27

42. Matlin KS, Reggio H, Helenius A, Simons K. Infectious entry pathway of influenza virus in a canine kidney cell line. J Cell Biol (1981) 91(3 Pt 1): 601-13. doi:10.1083/jcb.91.3.601 
43. Ochiai H, Sakai S, Hirabayashi T, Shimizu Y, Terasawa K. Inhibitory effect of bafilomycin A1, a specific inhibitor of vacuolar-type proton pump, on the growth of influenza A and B viruses in MDCK cells. Antiviral Res (1995) 27(4):425-30. doi:10.1016/0166-3542(95)00040-S

44. Yeganeh B, Ghavami S, Kroeker AL, Mahood TH, Stelmack GL, Klonisch T, et al. Suppression of influenza A virus replication in human lung epithelial cells by noncytotoxic concentrations bafilomycin A1. Am J Physiol Lung Cell Mol Physiol (2015) 308(3):L270-86. doi:10.1152/ajplung.00011.2014

45. Sorensen MG, Henriksen K, Neutzsky-Wulff AV, Dziegiel MH, Karsdal MA. Diphyllin, a novel and naturally potent V-ATPase inhibitor, abrogates acidification of the osteoclastic resorption lacunae and bone resorption. J Bone Miner Res (2007) 22(10):1640-8. doi:10.1359/jbmr.070613

46. Chen HW, Cheng JX, Liu MT, King K, Peng JY, Zhang XQ, et al. Inhibitory and combinatorial effect of diphyllin, a v-ATPase blocker, on influenza viruses. Antiviral Res (2013) 99(3):371-82. doi:10.1016/j.antiviral.2013.06.014

47. Diamond MS, Farzan M. The broad-spectrum antiviral functions of IFIT and IFITM proteins. Nat Rev Immunol (2013) 13(1):46-57. doi:10.1038/ nri3344

48. Shi G, Schwartz O, Compton AA. More than meets the I: the diverse antiviral and cellular functions of interferon-induced transmembrane proteins. Retrovirology (2017) 14(1):53. doi:10.1186/s12977-017-0377-y

49. Perreira JM, Chin CR, Feeley EM, Brass AL. IFITMs restrict the replication of multiple pathogenic viruses. J Mol Biol (2013) 425(24):4937-55. doi:10.1016/j.jmb.2013.09.024

50. Li K, Markosyan RM, Zheng YM, Golfetto O, Bungart B, Li M, et al. IFITM proteins restrict viral membrane hemifusion. PLoS Pathog (2013) 9(1):e1003124. doi:10.1371/journal.ppat.1003124

51. Amini-Bavil-Olyaee S, Choi YJ, Lee JH, Shi M, Huang IC, Farzan M, et al. The antiviral effector IFITM3 disrupts intracellular cholesterol homeostasis to block viral entry. Cell Host Microbe (2013) 13(4):452-64. doi:10.1016/j. chom.2013.03.006

52. Lee J, Kim J, Son K, d'Alexandry d'Orengiani AP, Min JY. Acid phosphatase 2 (ACP2) is required for membrane fusion during influenza virus entry. $S c i$ Rep (2017) 7:43893. doi:10.1038/srep43893

53. Desai TM, Marin M, Chin CR, Savidis G, Brass AL, Melikyan GB. IFITM3 restricts influenza A virus entry by blocking the formation of fusion pores following virus-endosome hemifusion. PLoS Pathog (2014) 10(4):e1004048. doi:10.1371/journal.ppat.1004048

54. Ma H, Kien F, Maniere M, Zhang Y, Lagarde N, Tse KS, et al. Human annexin A6 interacts with influenza a virus protein M2 and negatively modulates infection. J Virol (2012) 86(3):1789-801. doi:10.1128/JVI.06003-11

55. Musiol A, Gran S, Ehrhardt C, Ludwig S, Grewal T, Gerke V, et al. Annexin A6-balanced late endosomal cholesterol controls influenza A replication and propagation. MBio (2013) 4(6):e608-13. doi:10.1128/mBio. 00608-13

56. Hu Y, Jiang L, Lai W, Qin Y, Zhang T, Wang S, et al. MicroRNA-33a disturbs influenza A virus replication by targeting ARCN1 and inhibiting viral ribonucleoprotein activity. J Gen Virol (2016) 97(1):27-38. doi:10.1099/jgv. 0.000311

57. Xu X, Kedlaya R, Higuchi H, Ikeda S, Justice MJ, Setaluri V, et al. Mutation in archain 1, a subunit of COPI coatomer complex, causes diluted coat color and Purkinje cell degeneration. PLoS Genet (2010) 6(5):e1000956. doi:10.1371/ journal.pgen.1000956

58. Sun E, He J, Zhuang X. Dissecting the role of COPI complexes in influenza virus infection. J Virol (2013) 87(5):2673-85. doi:10.1128/JVI.02277-12

59. Eisfeld AJ, Neumann G, Kawaoka Y. At the centre: influenza A virus ribonucleoproteins. Nat Rev Microbiol (2015) 13(1):28-41. doi:10.1038/nrmicro3367

60. Babcock HP, Chen C, Zhuang X. Using single-particle tracking to study nuclear trafficking of viral genes. Biophys J (2004) 87(4):2749-58. doi:10.1529/ biophysj.104.042234

61. Resa-Infante P, Paterson D, Bonet J, Otte A, Oliva B, Fodor E, et al. Targeting importin-alpha7 as a therapeutic approach against pandemic influenza viruses. J Virol (2015) 89(17):9010-20. doi:10.1128/JVI.00583-15

62. Gabriel G, Klingel K, Otte A, Thiele S, Hudjetz B, Arman-Kalcek G, et al. Differential use of importin-alpha isoforms governs cell tropism and host adaptation of influenza virus. Nat Commun (2011) 2:156. doi:10.1038/ ncomms 1158

63. Rosenblatt JE. Antiparasitic agents. Mayo Clin Proc (1992) 67(3):276-87. doi:10.1016/S0025-6196(12)60105-0
64. Wagstaff KM, Sivakumaran H, Heaton SM, Harrich D, Jans DA. Ivermectin is a specific inhibitor of importin alpha/beta-mediated nuclear import able to inhibit replication of HIV-1 and dengue virus. Biochem J (2012) 443(3):851-6. doi:10.1042/BJ20120150

65. Gotz V, Magar L, Dornfeld D, Giese S, Pohlmann A, Hoper D, et al. Influenza A viruses escape from MxA restriction at the expense of efficient nuclear vRNP import. Sci Rep (2016) 6:23138. doi:10.1038/srep23138

66. Mor A, White A, Zhang K, Thompson M, Esparza M, Munoz-Moreno R, et al. Influenza virus mRNA trafficking through host nuclear speckles. Nat Microbiol (2016) 1(7):16069. doi:10.1038/nmicrobiol.2016.69

67. Dubois J, Terrier O, Rosa-Calatrava M. Influenza viruses and mRNA splicing: doing more with less. MBio (2014) 5(3):e70-14. doi:10.1128/mBio. 00070-14

68. Bullock AN, Das S, Debreczeni JE, Rellos P, Fedorov O, Niesen FH, et al. Kinase domain insertions define distinct roles of CLK kinases in SR protein phosphorylation. Structure (2009) 17(3):352-62. doi:10.1016/j.str.2008. 12.023

69. Zu M, Li C, Fang JS, Lian WW, Liu AL, Zheng LS, et al. Drug discovery of host CLK1 inhibitors for influenza treatment. Molecules (2015) 20(11):19735-47. doi:10.3390/molecules201119653

70. Amorim MJ, Read EK, Dalton RM, Medcalf L, Digard P. Nuclear export of influenza A virus mRNAs requires ongoing RNA polymerase II activity. Traffic (2007) 8(1):1-11. doi:10.1111/j.1600-0854.2006.00507.x

71. Utine CA, Stern M, Akpek EK. Clinical review: topical ophthalmic use of cyclosporin A. Ocul Immunol Inflamm (2010) 18(5):352-61. doi:10.3109/ 09273948.2010 .498657

72. Liu X, Zhao Z, Li Z, Xu C, Sun L, Chen J, et al. Cyclosporin A inhibits the influenza virus replication through cyclophilin A-dependent and -independent pathways. PLoS One (2012) 7(5):e37277. doi:10.1371/journal.pone.0037277

73. Ma C, Li F, Musharrafieh RG, Wang J. Discovery of cyclosporine A and its analogs as broad-spectrum anti-influenza drugs with a high in vitro genetic barrier of drug resistance. Antiviral Res (2016) 133:62-72. doi:10.1016/j. antiviral.2016.07.019

74. Read EK, Digard P. Individual influenza A virus mRNAs show differential dependence on cellular NXF1/TAP for their nuclear export. JGen Virol (2010) 91(Pt 5):1290-301. doi:10.1099/vir.0.018564-0

75. Morita M, Kuba K, Ichikawa A, Nakayama M, Katahira J, Iwamoto R, et al. The lipid mediator protectin D1 inhibits influenza virus replication and improves severe influenza. Cell (2013) 153(1):112-25. doi:10.1016/j.cell.2013. 02.027

76. Cencic R, Pelletier J. Hippuristanol - a potent steroid inhibitor of eukaryotic initiation factor 4A. Translation (Austin) (2016) 4(1):e1137381. doi:10.1080/ 21690731.2015.1137381

77. Sokabe M, Fraser CS. A helicase-independent activity of eIF4A in promoting mRNA recruitment to the human ribosome. Proc Natl Acad Sci U S A (2017) 114(24):6304-9. doi:10.1073/pnas.1620426114

78. Muller C, Schulte FW, Lange-Grunweller K, Obermann W, Madhugiri R, Pleschka S, et al. Broad-spectrum antiviral activity of the eIF4A inhibitor silvestrol against corona- and picornaviruses. Antiviral Res (2017) 150:123-9. doi:10.1016/j.antiviral.2017.12.010

79. Yanguez E, Castello A, Welnowska E, Carrasco L, Goodfellow I, Nieto A. Functional impairment of eIF4A and eIF4G factors correlates with inhibition of influenza virus mRNA translation. Virology (2011) 413(1):93-102. doi:10.1016/j.virol.2011.02.012

80. Slaine PD, Kleer M, Smith NK, Khaperskyy DA, McCormick C. Stress granule-inducing eukaryotic translation initiation factor $4 \mathrm{~A}$ inhibitors block influenza A virus replication. Viruses (2017) 9(12):E388. doi:10.3390/ v9120388

81. Malina A, Mills JR, Pelletier J. Emerging therapeutics targeting mRNA translation. Cold Spring Harb Perspect Biol (2012) 4(4):a012377. doi:10.1101/ cshperspect.a012377

82. Rossignol JF, La Frazia S, Chiappa L, Ciucci A, Santoro MG. Thiazolides, a new class of anti-influenza molecules targeting viral hemagglutinin at the post-translational level. J Biol Chem (2009) 284(43):29798-808. doi:10.1074/ jbc.M109.029470

83. Rossignol JF. Nitazoxanide: a first-in-class broad-spectrum antiviral agent. Antiviral Res (2014) 110:94-103. doi:10.1016/j.antiviral.2014.07.014

84. Tilmanis D, van Baalen C, Oh DY, Rossignol JF, Hurt AC. The susceptibility of circulating human influenza viruses to tizoxanide, the active 
metabolite of nitazoxanide. Antiviral Res (2017) 147:142-8. doi:10.1016/j. antiviral.2017.10.002

85. Belardo G, Cenciarelli O, La Frazia S, Rossignol JF, Santoro MG. Synergistic effect of nitazoxanide with neuraminidase inhibitors against influenza A viruses in vitro. Antimicrob Agents Chemother (2015) 59(2):1061-9. doi:10.1128/ AAC.03947-14

86. Lakdawala SS, Wu Y, Wawrzusin P, Kabat J, Broadbent AJ, Lamirande EW, et al. Influenza a virus assembly intermediates fuse in the cytoplasm. PLoS Pathog (2014) 10(3):e1003971. doi:10.1371/journal.ppat.1003971

87. Momose F, Sekimoto T, Ohkura T, Jo S, Kawaguchi A, Nagata K, et al. Apical transport of influenza A virus ribonucleoprotein requires Rab11-positive recycling endosome. PLoS One (2011) 6(6):e21123. doi:10.1371/journal. pone. 0021123

88. Kudo N, Khochbin S, Nishi K, Kitano K, Yanagida M, Yoshida M, et al. Molecular cloning and cell cycle-dependent expression of mammalian CRM1, a protein involved in nuclear export of proteins. J Biol Chem (1997) 272(47):29742-51. doi:10.1074/jbc.272.47.29742

89. Kohler A, Hurt E. Exporting RNA from the nucleus to the cytoplasm. Nat Rev Mol Cell Biol (2007) 8(10):761-73. doi:10.1038/nrm2255

90. Fischer U, Huber J, Boelens WC, Mattaj IW, Luhrmann R. The HIV-1 Rev activation domain is a nuclear export signal that accesses an export pathway used by specific cellular RNAs. Cell (1995) 82(3):475-83. doi:10.1016/ 0092-8674(95)90436-0

91. Brunotte L, Flies J, Bolte H, Reuther P, Vreede F, Schwemmle M. The nuclear export protein of H5N1 influenza A viruses recruits Matrix 1 (M1) protein to the viral ribonucleoprotein to mediate nuclear export. J Biol Chem (2014) 289(29):20067-77. doi:10.1074/jbc.M114.569178

92. Elton D, Simpson-Holley M, Archer K, Medcalf L, Hallam R, McCauley J, et al. Interaction of the influenza virus nucleoprotein with the cellular CRM1mediated nuclear export pathway. J Virol (2001) 75(1):408-19. doi:10.1128/ JVI.75.1.408-419.2001

93. Watanabe K, Takizawa N, Katoh M, Hoshida K, Kobayashi N, Nagata K. Inhibition of nuclear export of ribonucleoprotein complexes of influenza virus by leptomycin B. Virus Res (2001) 77(1):31-42. doi:10.1016/S0168-1702 (01)00263-5

94. Newlands ES, Rustin GJ, Brampton MH. Phase I trial of elactocin. Br J Cancer (1996) 74(4):648-9. doi:10.1038/bjc.1996.415

95. Perwitasari O, Johnson S, Yan X, Howerth E, Shacham S, Landesman Y, et al. Verdinexor, a novel selective inhibitor of nuclear export, reduces influenza a virus replication in vitro and in vivo. J Virol (2014) 88(17):10228-43. doi:10.1128/JVI.01774-14

96. Perwitasari O, Johnson S, Yan X, Register E, Crabtree J, Gabbard J, et al. Antiviral efficacy of verdinexor in vivo in two animal models of influenza A virus infection. PLoS One (2016) 11(11):e0167221. doi:10.1371/journal. pone. 0167221

97. Muthuri SG, Venkatesan S, Myles PR, Leonardi-Bee J, Al Khuwaitir TS, Al Mamun A, et al. Effectiveness of neuraminidase inhibitors in reducing mortality in patients admitted to hospital with influenza A H1N1pdm09 virus infection: a meta-analysis of individual participant data. Lancet Respir Med (2014) 2(5):395-404. doi:10.1016/S2213-2600(14)70041-4

98. Chutiwitoonchai N, Mano T, Kakisaka M, Sato H, Kondoh Y, Osada H, et al. Inhibition of CRM1-mediated nuclear export of influenza A nucleoprotein and nuclear export protein as a novel target for antiviral drug development. Virology (2017) 507:32-9. doi:10.1016/j.virol.2017.04.001

99. Li J, Chen C, Wong G, Dong W, Zheng W, Li Y, et al. Cyclophilin A protects mice against infection by influenza A virus. Sci Rep (2016) 6:28978. doi:10.1038/srep28978

100. Liu X, Sun L, Yu M, Wang Z, Xu C, Xue Q, et al. Cyclophilin A interacts with influenza $A$ virus $M 1$ protein and impairs the early stage of the viral replication. Cell Microbiol (2009) 11(5):730-41. doi:10.1111/j.1462-5822.2009. 01286.x

101. Liu X, Zhao Z, Xu C, Sun L, Chen J, Zhang L, et al. Cyclophilin A restricts influenza A virus replication through degradation of the M1 protein. PLoS One (2012) 7(2):e31063. doi:10.1371/journal.pone.0031063

102. Qiao Y, Yan Y, Tan KS, Tan SS, Seet JE, Arumugam TV, et al. CD151, a novel host factor of nuclear export signaling in influenza virus infection. J Allergy Clin Immunol (2018) 141(5):1799-817. doi:10.1016/j.jaci.2017.11.032

103. Gavara MM, Zaveri K, Badana AK, Gugalavath S, Amajala KC, Patnala K, et al. A novel small molecule inhibitor of CD151 inhibits proliferation of metastatic triple negative breast cancer cell lines. Proc Biochem (2018) 66:254-62. doi:10.1016/j.procbio.2017.12.004

104. Haidari M, Zhang W, Ganjehei L, Ali M, Chen Z. Inhibition of MLC phosphorylation restricts replication of influenza virus - a mechanism of action for anti-influenza agents. PLoS One (2011) 6(6):e21444. doi:10.1371/journal. pone.0021444

105. Pleschka S, Wolff T, Ehrhardt C, Hobom G, Planz O, Rapp UR, et al. Influenza virus propagation is impaired by inhibition of the Raf/MEK/ERK signalling cascade. Nat Cell Biol (2001) 3(3):301-5. doi:10.1038/35060098

106. Droebner K, Pleschka S, Ludwig S, Planz O. Antiviral activity of the MEKinhibitor U0126 against pandemic H1N1v and highly pathogenic avian influenza virus in vitro and in vivo. Antiviral Res (2011) 92(2):195-203. doi:10.1016/j.antiviral.2011.08.002

107. Ludwig S, Wolff T, Ehrhardt C, Wurzer WJ, Reinhardt J, Planz O, et al. MEK inhibition impairs influenza $B$ virus propagation without emergence of resistant variants. FEBS Lett (2004) 561(1-3):37-43. doi:10.1016/S00145793(04)00108-5

108. Planz O, Pleschka S, Ludwig S. MEK-specific inhibitor U0126 blocks spread of Borna disease virus in cultured cells. J Virol (2001) 75(10):4871-7. doi:10.1128/JVI.75.10.4871-4877.2001

109. Haasbach E, Muller C, Ehrhardt C, Schreiber A, Pleschka S, Ludwig S, et al. The MEK-inhibitor CI-1040 displays a broad anti-influenza virus activity in vitro and provides a prolonged treatment window compared to standard of care in vivo. Antiviral Res (2017) 142:178-84. doi:10.1016/j. antiviral.2017.03.024

110. Tcherniuk S, Cenac N, Comte M, Frouard J, Errazuriz-Cerda E, Galabov A, et al. Formyl peptide receptor 2 plays a deleterious role during influenza A virus infections. J Infect Dis (2016) 214(2):237-47. doi:10.1093/infdis/ jiw127

111. Courtin N, Fotso AF, Fautrad P, Mas F, Alessi MC, Riteau B. Antiviral activity of formyl peptide receptor 2 antagonists against influenza viruses. Antiviral Res (2017) 143:252-61. doi:10.1016/j.antiviral.2017.05.001

112. Grant BD, Donaldson JG. Pathways and mechanisms of endocytic recycling. Nat Rev Mol Cell Biol (2009) 10(9):597-608. doi:10.1038/nrm2755

113. Bruce EA, Stuart A, McCaffrey MW, Digard P. Role of the Rab11 pathway in negative-strand virus assembly. Biochem Soc Trans (2012) 40(6):1409-15. doi:10.1042/BST20120166

114. Amorim MJ, Bruce EA, Read EK, Foeglein A, Mahen R, Stuart AD, et al. A Rab11- and microtubule-dependent mechanism for cytoplasmic transport of influenza A virus viral RNA. J Virol (2011) 85(9):4143-56. doi:10.1128/ JVI.02606-10

115. Eisfeld AJ, Kawakami E, Watanabe T, Neumann G, Kawaoka Y. RAB11A is essential for transport of the influenza virus genome to the plasma membrane. J Virol (2011) 85(13):6117-26. doi:10.1128/JVI.00378-11

116. Bruce EA, Digard P, Stuart AD. The Rab11 pathway is required for influenza A virus budding and filament formation. J Virol (2010) 84(12):5848-59. doi:10.1128/JVI.00307-10

117. Ramos-Nascimento A, Kellen B, Ferreira F, Alenquer M, Vale-Costa S, Raposo G, et al. KIF13A mediates trafficking of influenza A virus ribonucleoproteins. J Cell Sci (2017) 130(23):4038-50. doi:10.1242/jcs.210807

118. Portran D, Schaedel L, Xu Z, Thery M, Nachury MV. Tubulin acetylation protects long-lived microtubules against mechanical ageing. Nat Cell Biol (2017) 19(4):391-8. doi:10.1038/ncb3481

119. Hubbert C, Guardiola A, Shao R, Kawaguchi Y, Ito A, Nixon A, et al. HDAC6 is a microtubule-associated deacetylase. Nature (2002) 417(6887):455-8. doi: $10.1038 / 417455 a$

120. Husain M, Cheung CY. Histone deacetylase 6 inhibits influenza A virus release by downregulating the trafficking of viral components to the plasma membrane via its substrate, acetylated microtubules. J Virol (2014) 88(19):11229-39. doi:10.1128/JVI.00727-14

121. Mori K, Haruyama T, Nagata K. Tamiflu-resistant but HA-mediated cell-to-cell transmission through apical membranes of cell-associated influenza viruses. PLoS One (2011) 6(11):e28178. doi:10.1371/journal.pone. 0028178

122. Roberts KL, Manicassamy B, Lamb RA. Influenza A virus uses intercellular connections to spread to neighboring cells. J Virol (2015) 89(3):1537-49. doi:10.1128/JVI.03306-14

123. Rossman JS, Lamb RA. Influenza virus assembly and budding. Virology (2011) 411(2):229-36. doi:10.1016/j.virol.2010.12.003 
124. Martyna A, Rossman J. Alterations of membrane curvature during influenza virus budding. Biochem Soc Trans (2014) 42(5):1425-8. doi:10.1042/ BST20140136

125. Elkins MR, Williams JK, Gelenter MD, Dai P, Kwon B, Sergeyev IV, et al. Cholesterol-binding site of the influenza M2 protein in lipid bilayers from solid-state NMR. Proc Natl Acad Sci U S A (2017) 114(49):12946-51. doi:10.1073/pnas.1715127114

126. Bajimaya S, Frankl T, Hayashi T, Takimoto T. Cholesterol is required for stability and infectivity of influenza A and respiratory syncytial viruses. Virology (2017) 510:234-41. doi:10.1016/j.virol.2017.07.024

127. Matsui K, Ozawa M, Kiso M, Yamashita M, Maekawa T, Kubota M, et al. Stimulation of alpha2-adrenergic receptors impairs influenza virus infection. Sci Rep (2018) 8(1):4631. doi:10.1038/s41598-018-22927-0

128. Herold S, Becker C, Ridge KM, Budinger GR. Influenza virus-induced lung injury: pathogenesis and implications for treatment. Eur Respir J (2015) 45(5):1463-78. doi:10.1183/09031936.00186214

129. Pulendran B, Maddur MS. Innate immune sensing and response to influenza. Curr Top Microbiol Immunol (2015) 386:23-71. doi:10.1007/82_2014_405

130. Chen X, Liu S, Goraya MU, Maarouf M, Huang S, Chen JL. Host immune response to influenza A virus infection. Front Immunol (2018) 9:320. doi:10.3389/fimmu.2018.00320

131. Kruger P, Saffarzadeh M, Weber AN, Rieber N, Radsak M, von Bernuth H, et al. Neutrophils: between host defence, immune modulation, and tissue injury. PLoS Pathog (2015) 11(3):e1004651. doi:10.1371/journal.ppat.1004651

132. Tate MD, Brooks AG, Reading PC. The role of neutrophils in the upper and lower respiratory tract during influenza virus infection of mice. Respir Res (2008) 9:57. doi:10.1186/1465-9921-9-57

133. Tate MD, Ioannidis LJ, Croker B, Brown LE, Brooks AG, Reading PC. The role of neutrophils during mild and severe influenza virus infections of mice. PLoS One (2011) 6(3):e17618. doi:10.1371/journal.pone.0017618

134. Lim K, Hyun YM, Lambert-Emo K, Capece T, Bae S, Miller R, et al. Neutrophil trails guide influenza-specific CD8(+) T cells in the airways. Science (2015) 349(6252):aaa4352. doi:10.1126/science.aaa4352

135. van Riel D, Leijten LM, van der Eerden M, Hoogsteden HC, Boven LA, Lambrecht $\mathrm{BN}$, et al. Highly pathogenic avian influenza virus H5N1 infects alveolar macrophages without virus production or excessive TNFalpha induction. PLoS Pathog (2011) 7(6):e1002099. doi:10.1371/journal. ppat.1002099

136. Seth S, Oberdorfer L, Hyde R, Hoff K, Thies V, Worbs T, et al. CCR7 essentially contributes to the homing of plasmacytoid dendritic cells to lymph nodes under steady-state as well as inflammatory conditions. JImmunol (2011) 186(6):3364-72. doi:10.4049/jimmunol.1002598

137. Qu C, Nguyen VA, Merad M, Randolph GJ. MHC class I/peptide transfer between dendritic cells overcomes poor cross-presentation by monocytederived APCs that engulf dying cells. J Immunol (2009) 182(6):3650-9. doi:10.4049/jimmunol.0801532

138. Allan RS, Waithman J, Bedoui S, Jones CM, Villadangos JA, Zhan Y, et al. Migratory dendritic cells transfer antigen to a lymph node-resident dendritic cell population for efficient CTL priming. Immunity (2006) 25(1):153-62. doi:10.1016/j.immuni.2006.04.017

139. Leon B, Ardavin C. Monocyte-derived dendritic cells in innate and adaptive immunity. Immunol Cell Biol (2008) 86(4):320-4. doi:10.1038/icb. 2008.14

140. Qu C, Brinck-Jensen NS, Zang M, Chen K. Monocyte-derived dendritic cells: targets as potent antigen-presenting cells for the design of vaccines against infectious diseases. Int J Infect Dis (2014) 19:1-5. doi:10.1016/j. ijid.2013.09.023

141. Swiecki M, Gilfillan S, Vermi W, Wang Y, Colonna M. Plasmacytoid dendritic cell ablation impacts early interferon responses and antiviral NK and CD8(+) T cell accrual. Immunity (2010) 33(6):955-66. doi:10.1016/j. immuni.2010.11.020

142. Hochrein H, Shortman K, Vremec D, Scott B, Hertzog P, O’Keeffe M. Differential production of IL-12, IFN-alpha, and IFN-gamma by mouse dendritic cell subsets. JImmunol (2001) 166(9):5448-55. doi:10.4049/ jimmunol.166.9.5448

143. Pipkin ME, Sacks JA, Cruz-Guilloty F, Lichtenheld MG, Bevan MJ, Rao A. Interleukin-2 and inflammation induce distinct transcriptional programs that promote the differentiation of effector cytolytic T cells. Immunity (2010) 32(1):79-90. doi:10.1016/j.immuni.2009.11.012
144. Luckheeram RV, Zhou R, Verma AD, Xia B. CD4(+)T cells: differentiation and functions. Clin Dev Immunol (2012) 2012:925135. doi:10.1155/2012/ 925135

145. Crotty S. T follicular helper cell differentiation, function, and roles in disease. Immunity (2014) 41(4):529-42. doi:10.1016/j.immuni.2014.10.004

146. Kurosaki T, Kometani K, Ise W. Memory B cells. Nat Rev Immunol (2015) 15(3):149-59. doi:10.1038/nri3802

147. Jameson SC, Masopust D. Understanding subset diversity in T cell memory. Immunity (2018) 48(2):214-26. doi:10.1016/j.immuni.2018.02.010

148. Obar JJ, Lefrancois L. Memory CD8+ T cell differentiation. Ann N Y Acad Sci (2010) 1183:251-66. doi:10.1111/j.1749-6632.2009.05126.x

149. MacLeod MK, Kappler JW, Marrack P. Memory CD4 T cells: generation, reactivation and re-assignment. Immunology (2010) 130(1):10-5. doi:10.1111/ j.1365-2567.2010.03260.x

150. Kong KF, Delroux K, Wang X, Qian F, Arjona A, Malawista SE, et al. Dysregulation of TLR3 impairs the innate immune response to West Nile virus in the elderly. J Virol (2008) 82(15):7613-23. doi:10.1128/JVI.00618-08

151. Openshaw PJ, Chiu C. Protective and dysregulated $\mathrm{T}$ cell immunity in RSV infection. Curr Opin Virol (2013) 3(4):468-74. doi:10.1016/j. coviro.2013.05.005

152. Hendrickson CM, Matthay MA. Viral pathogens and acute lung injury: investigations inspired by the SARS epidemic and the $2009 \mathrm{H} 1 \mathrm{~N} 1$ influenza pandemic. Semin Respir Crit Care Med (2013) 34(4):475-86. doi:10.1055/ s-0033-1351122

153. Cheung CY, Poon LL, Lau AS, Luk W, Lau YL, Shortridge KF, et al. Induction of proinflammatory cytokines in human macrophages by influenza A (H5N1) viruses: a mechanism for the unusual severity of human disease? Lancet (2002) 360(9348):1831-7. doi:10.1016/S0140-6736(02) 11772-7

154. Ye S, Lowther S, Stambas J. Inhibition of reactive oxygen species production ameliorates inflammation induced by influenza A viruses via upregulation of SOCS1 and SOCS3. J Virol (2015) 89(5):2672-83. doi:10.1128/JVI. 03529-14

155. Pauli EK, Schmolke M, Wolff T, Viemann D, Roth J, Bode JG, et al. Influenza A virus inhibits type I IFN signaling via NF-kappaB-dependent induction of SOCS-3 expression. PLoS Pathog (2008) 4(11):e1000196. doi:10.1371/ journal.ppat.1000196

156. Tumpey TM, Basler CF, Aguilar PV, Zeng H, Solorzano A, Swayne DE, et al. Characterization of the reconstructed 1918 Spanish influenza pandemic virus. Science (2005) 310(5745):77-80. doi:10.1126/science.1119392

157. Saffarzadeh M, Juenemann C, Queisser MA, Lochnit G, Barreto G, Galuska SP, et al. Neutrophil extracellular traps directly induce epithelial and endothelial cell death: a predominant role of histones. PLoS One (2012) 7(2):e32366. doi:10.1371/journal.pone.0032366

158. Tate MD, Deng YM, Jones JE, Anderson GP, Brooks AG, Reading PC. Neutrophils ameliorate lung injury and the development of severe disease during influenza infection. J Immunol (2009) 183(11):7441-50. doi:10.4049/ jimmunol.0902497

159. Narasaraju T, Yang E, Samy RP, Ng HH, Poh WP, Liew AA, et al. Excessive neutrophils and neutrophil extracellular traps contribute to acute lung injury of influenza pneumonitis. Am J Pathol (2011) 179(1):199-210. doi:10.1016/j. ajpath.2011.03.013

160. Hoeksema M, Tripathi S, White M, Qi L, Taubenberger J, van Eijk M, et al. Arginine-rich histones have strong antiviral activity for influenza A viruses. Innate Immun (2015) 21(7):736-45. doi:10.1177/1753425915593794

161. Ashar HK, Mueller NC, Rudd JM, Snider TA, Achanta M, Prasanthi M, et al. The role of extracellular histones in influenza virus pathogenesis. Am J Pathol (2018) 188(1):135-48. doi:10.1016/j.ajpath.2017.09.014

162. Zhu L, Liu L, Zhang Y, Pu L, Liu J, Li X, et al. High level of neutrophil extracellular traps correlates with poor prognosis of severe influenza A infection. J Infect Dis (2018) 217(3):428-37. doi:10.1093/infdis/jix475

163. Martinez NE, Zimmermann TJ, Goosmann C, Alexander T, Hedberg C, Ziegler S, et al. Tetrahydroisoquinolines: new inhibitors of Neutrophil Extracellular Trap (NET) formation. Chembiochem (2017) 18(10):888-93. doi:10.1002/cbic. 201600650

164. Kusunoki Y, Nakazawa D, Shida H, Hattanda F, Miyoshi A, Masuda S, et al. Peptidylarginine deiminase inhibitor suppresses neutrophil extracellular trap formation and MPO-ANCA production. Front Immunol (2016) 7:227. doi:10.3389/fimmu.2016.00227 
165. Hemmers S, Teijaro JR, Arandjelovic S, Mowen KA. PAD4-mediated neutrophil extracellular trap formation is not required for immunity against influenza infection. PLoS One (2011) 6(7):e22043. doi:10.1371/journal.pone. 0022043

166. Kim HY, Umetsu DT, Dekruyff RH. Innate lymphoid cells in asthma: will they take your breath away? Eur J Immunol (2016) 46(4):795-806. doi:10.1002/ eji.201444557

167. Monticelli LA, Sonnenberg GF, Artis D. Innate lymphoid cells: critical regulators of allergic inflammation and tissue repair in the lung. Curr Opin Immunol (2012) 24(3):284-9. doi:10.1016/j.coi.2012.03.012

168. Monticelli LA, Sonnenberg GF, Abt MC, Alenghat T, Ziegler CG, Doering TA, et al. Innate lymphoid cells promote lung-tissue homeostasis after infection with influenza virus. Nat Immunol (2011) 12(11):1045-54. doi:10.1031/ ni.2131

169. Jiao Y, Huntington ND, Belz GT, Seillet C. Type 1 innate lymphoid cell biology: lessons learnt from natural killer cells. Front Immunol (2016) 7:426. doi:10.3389/fimmu.2016.00426

170. Weizman OE, Adams NM, Schuster IS, Krishna C, Pritykin Y, Lau C, et al. ILC1 confer early host protection at initial sites of viral infection. Cell (2017) 171(4):795-808.e12. doi:10.1016/j.cell.2017.09.052

171. Califano D, Furuya Y, Roberts S, Avram D, McKenzie ANJ, Metzger DW. IFN- $\gamma$ increases susceptibility to influenza A infection through suppression of group II innate lymphoid cells. Mucosal Immunol (2017) 11(1):209-19. doi:10.1038/mi.2017.41

172. Cephus JY, Stier MT, Fuseini H, Yung JA, Toki S, Bloodworth MH, et al. Testosterone attenuates Group 2 innatelymphoid cell-mediated airway inflammation. Cell Rep (2017) 21(9):2487-99. doi:10.1016/j.celrep.2017.10.110

173. Doherty TA, Broide DH. Pathways to limit group 2 innate lymphoid cell activation. J Allergy Clin Immunol (2017) 139(5):1465-7. doi:10.1016/j.jaci. 2016.12.003

174. Vlahos R, Selemidis S. NADPH oxidases as novel pharmacologic targets against influenza A virus infection. Mol Pharmacol (2014) 86(6):747-59. doi:10.1124/mol.114.095216

175. Strengert M, Jennings R, Davanture S, Hayes P, Gabriel G, Knaus UG. Mucosal reactive oxygen species are required for antiviral response: role of Duox in influenza a virus infection. Antioxid Redox Signal (2014) 20(17):2695-709. doi:10.1089/ars.2013.5353

176. Kim HJ, Kim CH, Ryu JH, Kim MJ, Park CY, Lee JM, et al. Reactive oxygen species induce antiviral innate immune response through IFN-lambda regulation in human nasal epithelial cells. Am J Respir Cell Mol Biol (2013) 49(5):855-65. doi:10.1165/rcmb.2013-0003OC

177. To EE, Vlahos R, Luong R, Halls ML, Reading PC, King PT, et al. Endosomal NOX2 oxidase exacerbates virus pathogenicity and is a target for antiviral therapy. Nat Commun (2017) 8(1):69. doi:10.1038/s41467-01700057-x

178. Amatore D, Sgarbanti R, Aquilano K, Baldelli S, Limongi D, Civitelli L, et al. Influenza virus replication in lung epithelial cells depends on redoxsensitive pathways activated by NOX4-derived ROS. Cell Microbiol (2015) 17(1):131-45. doi:10.1111/cmi.12343

179. Lejal N, Truchet S, Bechor E, Bouguyon E, Khedkar V, Bertho N, et al. Turning off NADPH oxidase- 2 by impeding p67(phox) activation in infected mouse macrophages reduced viral entry and inflammation. Biochim Biophys Acta (2018) 1862(6):1263-75. doi:10.1016/j.bbagen.2018.03.004

180. Wind S, Beuerlein K, Eucker T, Muller H, Scheurer P, Armitage ME, et al. Comparative pharmacology of chemically distinct NADPH oxidase inhibitors. Br J Pharmacol (2010) 161(4):885-98. doi:10.1111/j.1476-5381.2010. 00920.x

181. Altenhofer S, Kleikers PW, Radermacher KA, Scheurer P, Rob Hermans JJ, Schiffers P, et al. The NOX toolbox: validating the role of NADPH oxidases in physiology and disease. Cell Mol Life Sci (2012) 69(14):2327-43. doi:10.1007/ s00018-012-1010-9

182. Heumuller S, Wind S, Barbosa-Sicard E, Schmidt HH, Busse R, Schroder K, et al. Apocynin is not an inhibitor of vascular NADPH oxidases but an antioxidant. Hypertension (2008) 51(2):211-7. doi:10.1161/HYPERTENSIONAHA.107. 100214

183. Vlahos R, Stambas J, Bozinovski S, Broughton BR, Drummond GR, Selemidis S. Inhibition of Nox2 oxidase activity ameliorates influenza A virus-induced lung inflammation. PLoS Pathog (2011) 7(2):e1001271. doi:10.1371/journal. ppat.1001271
184. Oostwoud LC, Gunasinghe P, Seow HJ, Ye JM, Selemidis S, Bozinovski S, et al. Apocynin and ebselen reduce influenza A virus-induced lung inflammation in cigarette smoke-exposed mice. Sci Rep (2016) 6:20983. doi:10.1038/ srep20983

185. Liu Q, Zhou YH, Yang ZQ. The cytokine storm of severe influenza and development of immunomodulatory therapy. Cell Mol Immunol (2016) 13(1):3-10. doi:10.1038/cmi.2015.74

186. Betakova T, Kostrabova A, Lachova V, Turianova L. Cytokines induced during influenza virus infection. Curr Pharm Des (2017) 23(18):2616-22. doi:10.2174/1381612823666170316123736

187. Julkunen I, Sareneva T, Pirhonen J, Ronni T, Melen K, Matikainen S. Molecular pathogenesis of influenza A virus infection and virus-induced regulation of cytokine gene expression. Cytokine Growth Factor Rev (2001) 12(2-3):171-80. doi:10.1016/S1359-6101(00)00026-5

188. Iwai A, Shiozaki T, Miyazaki T. Relevance of signaling molecules for apoptosis induction on influenza A virus replication. Biochem Biophys Res Commun (2013) 441(3):531-7. doi:10.1016/j.bbrc.2013.10.100

189. Zhou X, Jiang W, Liu Z, Liu S, Liang X. Virus infection and death receptormediated apoptosis. Viruses (2017) 9(11):E316. doi:10.3390/v9110316

190. To KK, Lau CC, Woo PC, Lau SK, Chan JF, Chan KH, et al. Human H7N9 virus induces a more pronounced pro-inflammatory cytokine but an attenuated interferon response in human bronchial epithelial cells when compared with an epidemiologically-linked chicken H7N9 virus. Virol J (2016) 13:42. doi:10.1186/s12985-016-0498-2

191. Quinn KM, Kan WT, Watson KA, Liddicoat BJ, Swan NG, McQuilten H, et al. Extrinsically derived TNF is primarily responsible for limiting antiviral CD8+ T cell response magnitude. PLoS One (2017) 12(9):e184732. doi:10.1371/journal.pone.0184732

192. DeBerge MP, Ely KH, Enelow RI. Soluble, but not transmembrane, TNF- $\alpha$ is required during influenza infection to limit the magnitude of immune responses and the extent of immunopathology. J Immunol (2014) 192(12):5839-51. doi:10.4049/jimmunol.1302729

193. van de Sandt CE, Barcena M, Koster AJ, Kasper J, Kirkpatrick CJ, Scott DP, et al. Human CD8(+) T cells damage noninfected epithelial cells during influenza virus infection in vitro. Am J Respir Cell Mol Biol (2017) 57(5):536-46. doi:10.1165/rcmb.2016-0377OC

194. Brincks EL, Woodland DL. Novel roles for IL-15 in T cell survival. F1000 Biol Rep (2010) 2:67. doi:10.3410/B2-67

195. Gagnon J, Ramanathan S, Leblanc C, Cloutier A, McDonald PP, Ilangumaran S. IL-6, in synergy with IL-7 or IL-15, stimulates TCR-independent proliferation and functional differentiation of CD8+ T lymphocytes. J Immunol (2008) 180(12):7958-68. doi:10.4049/jimmunol.180.12.7958

196. Damjanovic D, Divangahi M, Kugathasan K, Small CL, Zganiacz A, Brown EG, et al. Negative regulation of lung inflammation and immunopathology by TNF-alpha during acute influenza infection. Am J Pathol (2011) 179(6): 2963-76. doi:10.1016/j.ajpath.2011.09.003

197. Yang G, Hamacher J, Gorshkov B, White R, Sridhar S, Verin A, et al. The dual role of TNF in pulmonary edema. J Cardiovas Dis Res (2010) 1(1):29-36. doi:10.4103/0975-3583.59983

198. DeBerge MP, Ely KH, Cheng GS, Enelow RI. ADAM17-mediated processing of TNF- $\alpha$ expressed by antiviral effector CD8+ T cells is required for severe T-cell-mediated lung injury. PLoS One (2013) 8(11):e79340. doi:10.1371/ journal.pone. 0079340

199. Hasegawa S, Matsushige T, Inoue H, Shirabe K, Fukano R, Ichiyama T. Serum and cerebrospinal fluid cytokine profile of patients with 2009 pandemic H1N1 influenza virus-associated encephalopathy. Cytokine (2011) 54(2):167-72. doi:10.1016/j.cyto.2011.01.006

200. Ichiyama T, Nishikawa M, Yoshitomi T, Hayashi T, Furukawa S. Tumor necrosis factor-alpha, interleukin- 1 beta, and interleukin- 6 in cerebrospinal fluid from children with prolonged febrile seizures. Comparison with acute encephalitis/encephalopathy. Neurology (1998) 50(2):407-11. doi:10.1212/ WNL.50.2.407

201. Ito $\mathrm{Y}$, Ichiyama $\mathrm{T}$, Kimura $\mathrm{H}$, Shibata $\mathrm{M}$, Ishiwada N, Kuroki $\mathrm{H}$, et al. Detection of influenza virus RNA by reverse transcription-PCR and proinflammatory cytokines in influenza-virus-associated encephalopathy. JMed Virol (1999) 58(4):420-5. doi:10.1002/(SICI) 1096-9071(199908)58:4<420::AIDJMV16>3.0.CO;2-T

202. Lv S, Song HL, Zhou Y, Li LX, Cui W, Wang W, et al. Tumour necrosis factor-alpha affects blood-brain barrier permeability and tight 
junction-associated occludin in acute liver failure. Liver Int (2010) 30(8): 1198-210. doi:10.1111/j.1478-3231.2010.02211.x

203. Tsuge M, Yasui K, Ichiyawa T, Saito Y, Nagaoka Y, Yashiro M, et al. Increase of tumor necrosis factor-alpha in the blood induces early activation of matrix metalloproteinase-9 in the brain. Microbiol Immunol (2010) 54(7):417-24. doi:10.1111/j.1348-0421.2010.00226.x

204. Kuperberg SJ, Wadgaonkar R. Sepsis-associated encephalopathy: the bloodbrain barrier and the sphingolipid rheostat. Front Immunol (2017) 8:597. doi:10.3389/fimmu.2017.00597

205. Shi X, Zhou W, Huang H, Zhu H, Zhou P, Zhu H, et al. Inhibition of the inflammatory cytokine tumor necrosis factor-alpha with etanercept provides protection against lethal H1N1 influenza infection in mice. Crit Care (2013) 17(6):R301. doi:10.1186/cc13171

206. Dienz O, Rud JG, Eaton SM, Lanthier PA, Burg E, Drew A, et al. Essential role of IL-6 in protection against H1N1 influenza virus by promoting neutrophil survival in the lung. Mucosal Immunol (2012) 5(3):258-66. doi:10.1038/ mi.2012.2

207. Yang ML, Wang CT, Yang SJ, Leu CH, Chen SH, Wu CL, et al. IL-6 ameliorates acute lung injury in influenza virus infection. Sci Rep (2017) 7:43829. doi:10.1038/srep43829

208. Pyle CJ, Uwadiae FI, Swieboda DP, Harker JA. Early IL-6 signalling promotes IL-27 dependent maturation of regulatory T cells in the lungs and resolution of viral immunopathology. PLoS Pathog (2017) 13(9):e1006640. doi:10.1371/ journal.ppat. 1006640

209. Aiba H, Mochizuki M, Kimura M, Hojo H. Predictive value of serum interleukin-6 level in influenza virus-associated encephalopathy. Neurology (2001) 57(2):295-9. doi:10.1212/WNL.57.2.295

210. Fukumoto Y, Okumura A, Hayakawa F, Suzuki M, Kato T, Watanabe K, et al. Serum levels of cytokines and EEG findings in children with influenza associated with mild neurological complications. Brain Dev (2007) 29(7):425-30. doi:10.1016/j.braindev.2006.12.005

211. Cohen SS, Min M, Cummings EE, Chen X, Sadowska GB, Sharma S, et al. Effects of interleukin- 6 on the expression of tight junction proteins in isolated cerebral microvessels from yearling and adult sheep. Neuroimmunomodulation (2013) 20(5):264-73. doi:10.1159/000350470

212. Song M, Winchester J, Albright RL, Capponi VJ, Choquette MD, Kellum JA. Cytokine removal with a novel adsorbent polymer. Blood Purif (2004) 22(5):428-34. doi:10.1159/000080235

213. Lees NJ, Rosenberg A, Hurtado-Doce AI, Jones J, Marczin N, Zeriouh M, et al. Combination of ECMO and cytokine adsorption therapy for severe sepsis with cardiogenic shock and ARDS due to Panton-Valentine leukocidin-positive Staphylococcus aureus pneumonia and H1N1. J Artif Organs (2016) 19(4):399-402. doi:10.1007/s10047-016-0915-8

214. Liu FD, Kenngott EE, Schroter MF, Kuhl A, Jennrich S, Watzlawick R, et al. Timed action of IL-27 protects from immunopathology while preserving defense in influenza. PLoS Pathog (2014) 10(5):e1004110. doi:10.1371/ journal.ppat. 1004110

215. Robinson KM, Lee B, Scheller EV, Mandalapu S, Enelow RI, Kolls JK, et al. The role of IL-27 in susceptibility to post-influenza Staphylococcus aureus pneumonia. Respir Res (2015) 16:10. doi:10.1186/s12931-015-0168-8

216. Krug RM. Functions of the influenza A virus NS1 protein in antiviral defense. Curr Opin Virol (2015) 12:1-6. doi:10.1016/j.coviro.2015.01.007

217. Jureka AS, Kleinpeter AB, Cornilescu G, Cornilescu CC, Petit CM. Structural basis for a novel interaction between the NS1 protein derived from the 1918 influenza virus and RIG-I. Structure (2015) 23(11):2001-10. doi:10.1016/j. str.2015.08.007

218. Ciancanelli MJ, Huang SX, Luthra P, Garner H, Itan Y, Volpi S, et al. Infectious disease. Life-threatening influenza and impaired interferon amplification in human IRF7 deficiency. Science (2015) 348(6233):448-53. doi:10.1126/ science.aaa1578

219. Davidson S, Maini MK, Wack A. Disease-promoting effects of type I interferons in viral, bacterial, and coinfections. J Interferon Cytokine Res (2015) 35(4):252-64. doi:10.1089/jir.2014.0227

220. Beilharz MW, Cummins JM, Bennett AL. Protection from lethal influenza virus challenge by oral type 1 interferon. Biochem Biophys Res Commun (2007) 355(3):740-4. doi:10.1016/j.bbrc.2007.02.019

221. Bennett AL, Smith DW, Cummins MJ, Jacoby PA, Cummins JM, Beilharz MW. Low-dose oral interferon alpha as prophylaxis against viral respiratory illness: a double-blind, parallel controlled trial during an influenza pandemic year. Influenza Other Respi Viruses (2013) 7(5):854-62. doi:10.1111/irv. 12094

222. Davidson S, McCabe TM, Crotta S, Gad HH, Hessel EM, Beinke S, et al. IFNlambda is a potent anti-influenza therapeutic without the inflammatory side effects of IFNalpha treatment. EMBO Mol Med (2016) 8(9):1099-112. doi:10.15252/emmm.201606413

223. Davidson S, Crotta S, McCabe TM, Wack A. Pathogenic potential of interferon alphabeta in acute influenza infection. Nat Commun (2014) 5:3864. doi: $10.1038 /$ ncomms 4864

224. Kim S, Kim MJ, Kim CH, Kang JW, Shin HK, Kim DY, et al. The superiority of IFN-lambda as a therapeutic candidate to control acute influenza viral lung infection. Am J Respir Cell Mol Biol (2017) 56(2):202-12. doi:10.1165/ rcmb.2016-0174OC

225. Li W, Moltedo B, Moran TM. Type I interferon induction during influenza virus infection increases susceptibility to secondary Streptococcus pneumoniae infection by negative regulation of gammadelta T cells. J Virol (2012) 86(22):12304-12. doi:10.1128/JVI.01269-12

226. Galani IE, Triantafyllia V, Eleminiadou EE, Koltsida O, Stavropoulos A, Manioudaki $\mathrm{M}$, et al. Interferon-lambda mediates non-redundant front-line antiviral protection against influenza virus infection without compromising host fitness. Immunity (2017) 46(5):875-890.e6. doi:10.1016/j.immuni.2017. 04.025

227. Coch C, Stumpel JP, Lilien-Waldau V, Wohlleber D, Kummerer BM, Bekeredjian-Ding I, et al. RIG-I activation protects and rescues from lethal influenza virus infection and bacterial superinfection. Mol Ther (2017) 25(9):2093-103. doi:10.1016/j.ymthe.2017.07.003

228. Lee SM, Gai WW, Cheung TK, Peiris JS. Antiviral effect of a selective COX-2 inhibitor on H5N1 infection in vitro. Antiviral Res (2011) 91(3):330-4. doi:10.1016/j.antiviral.2011.07.011

229. Li C, Li C, Zhang AJ, To KK, Lee AC, Zhu H, et al. Avian influenza A H7N9 virus induces severe pneumonia in mice without prior adaptation and responds to a combination of zanamivir and COX-2 inhibitor. PLoS One (2014) 9(9):e107966. doi:10.1371/journal.pone.0107966

230. Lee MY, Cheung CY, Peiris JS. Role of cyclooxygenase-2 in H5N1 viral pathogenesis and the potential use of its inhibitors. Hong Kong Med J (2013) 19(Suppl 4):S29-35.

231. Coulombe F, Jaworska J, Verway M, Tzelepis F, Massoud A, Gillard J, et al. Targeted prostaglandin E2 inhibition enhances antiviral immunity through induction of type I interferon and apoptosis in macrophages. Immunity (2014) 40(4):554-68. doi:10.1016/j.immuni.2014.02.013

232. Chen L, Fan J, Li Y, Shi X, Ju D, Yan Q, et al. Modified Jiu Wei Qiang Huo decoction improves dysfunctional metabolomics in influenza A pneumoniainfected mice. Biomed Chromatogr (2014) 28(4):468-74. doi:10.1002/bmc. 3055

233. Takeuchi O, Akira S. Pattern recognition receptors and inflammation. Cell (2010) 140(6):805-20. doi:10.1016/j.cell.2010.01.022

234. Le Goffic R, Pothlichet J, Vitour D, Fujita T, Meurs E, Chignard M, et al. Cutting edge: influenza A virus activates TLR3-dependent inflammatory and RIG-I-dependent antiviral responses in human lung epithelial cells. J Immunol (2007) 178(6):3368-72. doi:10.4049/jimmunol.178.6.3368

235. Lee SM, Kok KH, Jaume M, Cheung TK, Yip TF, Lai JC, et al. Toll-like receptor 10 is involved in induction of innate immune responses to influenza virus infection. Proc Natl Acad Sci U S A (2014) 111(10):3793-8. doi:10.1073/ pnas. 1324266111

236. Wu W, Zhang W, Duggan ES, Booth JL, Zou MH, Metcalf JP. RIG-I and TLR3 are both required for maximum interferon induction by influenza virus in human lung alveolar epithelial cells. Virology (2015) 482:181-8. doi:10.1016/j.virol.2015.03.048

237. Patel JR, Garcia-Sastre A. Activation and regulation of pathogen sensor RIG-I. Cytokine Growth Factor Rev (2014) 25(5):513-23. doi:10.1016/j. cytogfr.2014.08.005

238. Weber-Gerlach M, Weber F. Standing on three legs: antiviral activities of RIG-I against influenza viruses. Curr Opin Immunol (2016) 42:71-5. doi:10.1016/j.coi.2016.05.016

239. Yoneyama M, Onomoto K, Jogi M, Akaboshi T, Fujita T. Viral RNA detection by RIG-I-like receptors. Curr Opin Immunol (2015) 32:48-53. doi:10.1016/j. coi.2014.12.012

240. De Nardo D. Toll-like receptors: activation, signalling and transcriptional modulation. Cytokine (2015) 74(2):181-9. doi:10.1016/j.cyto.2015.02.025 
241. Kagan JC, Su T, Horng T, Chow A, Akira S, Medzhitov R. TRAM couples endocytosis of toll-like receptor 4 to the induction of interferon-beta. Nat Immunol (2008) 9(4):361-8. doi:10.1038/ni1569

242. Oosting M, Cheng SC, Bolscher JM, Vestering-Stenger R, Plantinga TS, Verschueren IC, et al. Human TLR10 is an anti-inflammatory patternrecognition receptor. Proc Natl Acad Sci U S A (2014) 111(42):E4478-84. doi:10.1073/pnas.1410293111

243. Jiang S, Li X, Hess NJ, Guan Y, Tapping RI. TLR10 is a negative regulator of both MyD88-dependent and -independent TLR signaling. J Immunol (2016) 196(9):3834-41. doi:10.4049/jimmunol.1502599

244. Lee SMY, Yip TF, Yan S, Jin DY, Wei HL, Guo RT, et al. Recognition of double-stranded RNA and regulation of interferon pathway by toll-like receptor 10. Front Immunol (2018) 9:516. doi:10.3389/fimmu.2018.00516

245. Imai Y, Kuba K, Neely GG, Yaghubian-Malhami R, Perkmann T, van Loo G, et al. Identification of oxidative stress and toll-like receptor 4 signaling as a key pathway of acute lung injury. Cell (2008) 133(2):235-49. doi:10.1016/j. cell.2008.02.043

246. Tsai SY, Segovia JA, Chang TH, Morris IR, Berton MT, Tessier PA, et al. DAMP molecule S100A9 acts as a molecular pattern to enhance inflammation during influenza A virus infection: role of DDX21-TRIF-TLR4-MyD88 pathway. PLoS Pathog (2014) 10(1):e1003848. doi:10.1371/journal.ppat. 1003848

247. Opal SM, Laterre PF, Francois B, LaRosa SP, Angus DC, Mira JP, et al. Effect of eritoran, an antagonist of MD2-TLR4, on mortality in patients with severe sepsis: the ACCESS randomized trial. JAMA (2013) 309(11):1154-62. doi:10.1001/jama.2013.2194

248. Shirey KA, Lai W, Scott AJ, Lipsky M, Mistry P, Pletneva LM, et al. The TLR4 antagonist eritoran protects mice from lethal influenza infection. Nature (2013) 497(7450):498-502. doi:10.1038/nature12118

249. Perrin-Cocon L, Aublin-Gex A, Sestito SE, Shirey KA, Patel MC, Andre P, et al. TLR4 antagonist FP7 inhibits LPS-induced cytokine production and glycolytic reprogramming in dendritic cells, and protects mice from lethal influenza infection. Sci Rep (2017) 7:40791. doi:10.1038/srep40791

250. Piao W, Shirey KA, Ru LW, Lai W, Szmacinski H, Snyder GA, et al. A decoy peptide that disrupts TIRAP recruitment to TLRs is protective in a murine model of influenza. Cell Rep (2015) 11(12):1941-52. doi:10.1016/j. celrep.2015.05.035

251. Shirey KA, Lai W, Patel MC, Pletneva LM, Pang C, Kurt-Jones E, et al. Novel strategies for targeting innate immune responses to influenza. Mucosal Immunol (2016) 9(5):1173-82. doi:10.1038/mi.2015.141

252. Leung YH, Nicholls JM, Ho CK, Sia SF, Mok CK, Valkenburg SA, et al. Highly pathogenic avian influenza A H5N1 and pandemic H1N1 virus infections have different phenotypes in toll-like receptor 3 knockout mice. J Gen Virol (2014) 95(Pt 9):1870-9. doi:10.1099/vir.0.066258-0

253. Gao W, Xiong Y, Li Q, Yang H. Inhibition of toll-like receptor signaling as a promising therapy for inflammatory diseases: a journey from molecular to nano therapeutics. Front Physiol (2017) 8:508. doi:10.3389/fphys.2017.00508

254. Cheng K, Wang X, Yin H. Small-molecule inhibitors of the TLR3/dsRNA complex. J Am Chem Soc (2011) 133(11):3764-7. doi:10.1021/ja111312h

255. Li Z, Li L, Zhou H, Zeng L, Chen T, Chen Q, et al. Radix isatidis polysaccharides inhibit influenza a virus and influenza A virus-induced inflammation via suppression of Host TLR3 signaling in vitro. Molecules (2017) 22(1):E116. doi:10.3390/molecules22010116
256. Tian J, Jiao X, Wang X, Geng J, Wang R, Liu N, et al. Novel effect of methionine enkephalin against influenza A virus infection through inhibiting TLR7MyD88-TRAF6-NF-kappaB p65 signaling pathway. Int Immunopharmacol (2017) 55:38-48. doi:10.1016/j.intimp.2017.12.001

257. Hulme KD, Gallo LA, Short KR. Influenza virus and glycemic variability in diabetes: a killer combination? Front Microbiol (2017) 8:861. doi:10.3389/ fmicb.2017.00861

258. Kohio HP, Adamson AL. Glycolytic control of vacuolar-type ATPase activity: a mechanism to regulate influenza viral infection. Virology (2013) 444(1-2):301-9. doi:10.1016/j.virol.2013.06.026

259. Miyake-Stoner SJ, O'Shea CC. Metabolism goes viral. Cell Metab (2014) 19(4):549-50. doi:10.1016/j.cmet.2014.03.022

260. Munger J, Bajad SU, Coller HA, Shenk T, Rabinowitz JD. Dynamics of the cellular metabolome during human cytomegalovirus infection. PLoS Pathog (2006) 2(12):e132. doi:10.1371/journal.ppat.0020132

261. Koyuncu E, Purdy JG, Rabinowitz JD, Shenk T. Saturated very long chain fatty acids are required for the production of infectious human cytomegalovirus progeny. PLoS Pathog (2013) 9(5):e1003333. doi:10.1371/journal. ppat. 1003333

262. Goodwin CM, Xu S, Munger J. Stealing the keys to the kitchen: viral manipulation of the host cell metabolic network. Trends Microbiol (2015) 23(12):789-98. doi:10.1016/j.tim.2015.08.007

263. Sanchez EL, Lagunoff M. Viral activation of cellular metabolism. Virology (2015) 47(9-480):609-18. doi:10.1016/j.virol.2015.02.038

264. Smallwood HS, Duan S, Morfouace M, Rezinciuc S, Shulkin BL, Shelat A, et al. Targeting metabolic reprogramming by influenza infection for therapeutic intervention. Cell Rep (2017) 19(8):1640-53. doi:10.1016/j.celrep. 2017.04.039

265. Ritter JB, Wahl AS, Freund S, Genzel Y, Reichl U. Metabolic effects of influenza virus infection in cultured animal cells: Intra- and extracellular metabolite profiling. BMC Syst Biol (2010) 4:61. doi:10.1186/1752-0509-4-61

266. Ryan DG, O'Neill LAJ. Krebs cycle rewired for macrophage and dendritic cell effector functions. FEBS Lett (2017) 591(19):2992-3006. doi:10.1002/1873-3468.12744

267. Tannahill GM, Curtis AM, Adamik J, Palsson-McDermott EM, McGettrick AF, Goel G, et al. Succinate is an inflammatory signal that induces IL-1beta through HIF-1alpha. Nature (2013) 496(7444):238-42. doi:10.1038/nature11986

268. Mills EL, Ryan DG, Prag HA, Dikovskaya D, Menon D, Zaslona Z, et al. Itaconate is an anti-inflammatory metabolite that activates Nrf2 via alkylation of KEAP1. Nature (2018) 556(7699):113-7. doi:10.1038/nature25986

Conflict of Interest Statement: The authors declare that the research was conducted in the absence of any commercial or financial relationships that could be construed as a potential conflict of interest.

Copyright (๑) 2018 Yip, Selim, Lian and Lee. This is an open-access article distributed under the terms of the Creative Commons Attribution License (CC BY). The use, distribution or reproduction in other forums is permitted, provided the original author(s) and the copyright owner(s) are credited and that the original publication in this journal is cited, in accordance with accepted academic practice. No use, distribution or reproduction is permitted which does not comply with these terms. 